\title{
1 Anaerobic sulfur oxidation underlies adaptation of a chemosynthetic symbiont \\ 2 to oxic-anoxic interfaces
}

4 Running title: chemosynthetic ectosymbiont's response to oxygen

5

6 Gabriela F. Paredes ${ }^{1}$, Tobias Viehboeck ${ }^{1,2}$, Raymond Lee ${ }^{3}$, Marton Palatinszky²,

7 Michaela A. Mausz ${ }^{4}$, Siegfried Reipert ${ }^{5}$, Arno Schintlmeister ${ }^{2,6}$, Andreas Maier ${ }^{7}$, Jean-

8 Marie Volland ${ }^{1, *}$, Claudia Hirschfeld ${ }^{8}$, Michael Wagner ${ }^{2,9}$, David Berry ${ }^{2,10}$, Stephanie

9 Markert ${ }^{8}$, Silvia Bulgheresi ${ }^{1, \#}$ and Lena König ${ }^{1 \#}$

111 University of Vienna, Department of Functional and Evolutionary Ecology,

2 University of Vienna, Center for Microbiology and Environmental Systems Science,

${ }^{3}$ Washington State University, School of Biological Sciences, Pullman, WA, USA

${ }^{4}$ University of Warwick, School of Life Sciences, Coventry, UK

${ }^{5}$ University of Vienna, Core Facility Cell Imaging and Ultrastructure Research, Vienna, 
6 University of Vienna, Center for Microbiology and Environmental Systems Science, Large-Instrument Facility for Environmental and Isotope Mass Spectrometry, Vienna, Austria

${ }^{7}$ University of Vienna, Faculty of Geosciences, Geography, and Astronomy, Department of Geography and Regional Research, Geoecology, Vienna, Austria

8 University of Greifswald, Institute of Pharmacy, Department of Pharmaceutical Biotechnology, Greifswald, Germany

${ }^{9}$ Aalborg University, Department of Chemistry and Bioscience, Aalborg, Denmark

10 Joint Microbiome Facility of the Medical University of Vienna and the University of Vienna, Vienna, Austria

*Present affiliation: Joint Genome Institute/Global Viral, San Francisco, CA, USA

\#Address correspondence to Silvia Bulgheresi, silvia.bulgheresi@univie.ac.at.

\#Address correspondence to Lena König, lena.koenig@univie.ac.at.

Silvia Bulgheresi and Lena König contributed equally to this work. 


\section{ABSTRACT}

Chemosynthetic symbioses occur worldwide in marine habitats, but comprehensive physiological studies of chemoautotrophic bacteria thriving on animals are scarce. Stilbonematinae are coated by monocultures of thiotrophic Gammaproteobacteria. As these nematodes migrate through the redox zone, their ectosymbionts experience varying oxygen concentrations. However, nothing is known about how these variations affect their physiology or metabolism. Here, by applying omics, Raman microspectroscopy and stable isotope labelling, we investigated the effect of oxygen on Candidatus Thiosymbion oneisti. Unexpectedly, sulfur oxidation genes were upregulated in anoxic relative to oxic conditions, but carbon fixation genes and incorporation of ${ }^{13} \mathrm{C}$-labeled bicarbonate were not. Instead, several genes involved in carbon fixation were upregulated in oxic conditions, together with genes involved in organic carbon assimilation, polyhydroxyalkanoate (PHA) biosynthesis, nitrogen fixation and urea utilization. Furthermore, in the presence of oxygen, stress-related genes were upregulated together with vitamin biosynthesis genes likely necessary to withstand its deleterious effects, and the symbiont appeared to proliferate less. Based on its physiological response to oxygen, we propose that $C a$. T. oneisti may exploit anaerobic sulfur oxidation coupled to denitrification to proliferate in anoxic sand. However, the ectosymbiont would still profit from the oxygen available in superficial sand, as the energy-efficient aerobic respiration would facilitate carbon and nitrogen assimilation by the ectosymbiont.

IMPORTANCE Chemoautotrophic endosymbionts are famous for exploiting sulfur oxidization to feed marine organisms with fixed carbon. However, the physiology of thiotrophic bacteria thriving on the surface of animals (ectosymbionts) is less 
understood. One long standing hypothesis posits that attachment to animals that migrate between reduced and oxic environments would boost sulfur oxidation, as the ectosymbionts would alternatively access sulfide and oxygen, the most favorable electron acceptor. Here, we investigated the effect of oxygen on the physiology of Candidatus Thiosymbion oneisti, a Gammaproteobacterium which lives attached to marine nematodes inhabiting shallow water sand. Surprisingly, sulfur oxidation genes were upregulated in anoxic relative to oxic conditions. Furthermore, under anoxia, the ectosymbiont appeared to be less stressed and to proliferate more. We propose that animal-mediated access to oxygen, rather than enhancing sulfur oxidation, would facilitate assimilation of carbon and nitrogen by the ectosymbiont.

\section{INTRODUCTION}

At least six animal phyla and numerous lineages of bacterial symbionts belonging to Alphaproteobacteria, Gammaproteobacteria, and Campylobacteria (formerly Epsilonproteobacteria) (1) engage in chemosynthetic symbioses, rendering the evolutionary success of these associations incontestable (2, 3). Many of these mutualistic associations rely on sulfur-oxidizing (thiotrophic), chemoautotrophic bacterial symbionts. These oxidize reduced sulfur compounds for energy generation in order to fix inorganic carbon $\left(\mathrm{CO}_{2}\right)$ for biomass build-up. Particularly in binary symbioses involving thiotrophic endosymbionts, it is generally accepted that the bacterial chemosynthetic metabolism serves to provide organic carbon for feeding the animal host (reviewed in 2-4). In addition, some chemosynthetic symbionts have been found capable to fix atmospheric nitrogen, albeit symbiont-to-host transfer of fixed nitrogen remains unproven $(5,6)$. As for the rarer chemosynthetic bacterial-animal associations in which symbionts colonize exterior surfaces (ectosymbioses), fixation of inorganic 
carbon and transfer of organic carbon to the host has only been unequivocally shown for the microbial community colonizing the gill chamber of the hydrothermal vent shrimp Rimicaris exoculata (7).

The majority of thioautotrophic symbioses have been described to rely on reduced sulfur compounds as electron donors and oxygen as terminal electron acceptor $(3,4)$. However, given that sulfidic and oxic zones are often spatially separated, also owing to abiotic sulfide oxidation (8, 9), chemosynthetic symbioses (1) are typically found where sulfide and oxygen occur in close proximity (e.g. hydrothermal vents, shallowwater sediments) and/or (2) exhibit host behavioral, physiological and anatomical adaptations enabling the symbionts to access both substrates. Among the former adaptations, host-mediated migration across oxygen and sulfide gradients was proposed for shallow water interstitial invertebrates and Kentrophoros ciliates (reviewed in 2,3 ). The symbionts of Stilbonematinae have also long been hypothesized to associate with their motile nematode hosts to maximize sulfur oxidation-fueled chemosynthesis, by alternatively accessing oxygen in upper sand layers and sulfide in deeper, anoxic sand. This hypothesis was based upon the distribution pattern of Stilbonematinae in sediment cores together with their migration patterns observed in agar columns $(10,11,12)$. However, several chemosynthetic symbionts were subsequently shown to use nitrate as an alternative electron acceptor, and nitrate respiration was stimulated by sulfide, suggesting that symbionts may gain energy by respiring nitrate instead of oxygen (13-16). Furthermore, although physiological studies on chemosynthetic symbioses are available (e.g. 17-19), the impact of oxygen on the symbiont central metabolism has not been investigated (remarkably, not even in those that are directly exposed to fluctuating concentrations thereof as in the case of ectosymbionts). 

surface of the marine nematode Laxus oneistus (Stilbonematinae). This group of freeliving roundworms represents the only known animals engaging in monospecific ectosymbioses, i.e. each nematode species is ensheathed by a single $\mathrm{Ca}$. Thiosymbion phylotype, and, in the case of $\mathrm{Ca}$. T. oneisti, the bacteria form a single layer on the cuticle of its host (20-24). Moreover, the rod-shaped representatives of this bacterial genus, including Ca. T. oneisti, divide by FtsZ-based longitudinal fission, a unique reproductive strategy which ensures continuous and transgenerational host-attachment (25-27). chemoautotrophic sulfur oxidizers based on several lines of evidence: stable carbon isotope ratios of symbiotic nematodes are comparable to those found in other chemosynthetic symbioses (10); the key enzyme for carbon fixation via the CalvinBenson-Bassham cycle (RuBisCO) along with elemental sulfur and enzymes involved in sulfur oxidation have been detected (28-30); reduced sulfur compounds (sulfide, thiosulfate) have been shown to be taken up from the environment by the ectosymbionts, to be used as energy source, and to be responsible for the white appearance of the symbiotic nematodes $(11,13,30)$; the animals often occur in the sulfidic zone of marine shallow-water sands (12). More recently, the phylogenetic placement and genetic repertoire of $\mathrm{Ca}$. Thiosymbion species have equally been supporting the chemosynthetic nature of the symbiosis $(6,24)$. In this study, we incubated nematodes associated with Ca. T. oneisti under conditions resembling those encountered in their natural environment, and subsequently examined the ectosymbiont transcriptional responses via RNA sequencing (RNA-Seq). 
150

151

In combination with complementary methods such as stable isotope-labeling, proteomics, Raman microspectroscopy and lipidomics, we show that the ectosymbiont exhibits specific metabolic responses to oxygen. Most strikingly, sulfur oxidation but not carbon fixation was upregulated in anoxia. Such a response in their natural environment would challenge the current opinion that sulfur oxidation requires oxygen and drives carbon fixation in chemosynthetic symbioses. We finally present a metabolic scheme of a thiotrophic ectosymbiont experiencing ever-changing oxygen concentrations, in which anaerobic sulfur oxidation coupled to denitrification may represent the preferred metabolism for growth.

\section{MATERIALS AND METHODS}

\section{Sample collection}

Laxus oneistus individuals were collected on multiple field trips (2016-2019) at approximately $1 \mathrm{~m}$ depth from sand bars off the Smithsonian Field Station, Carrie Bow Cay in Belize $\left(16^{\circ} 48^{\prime} 11.01^{\prime \prime} \mathrm{N}, 88^{\circ} 4^{\prime} 54.42^{\prime \prime} \mathrm{W}\right)$. The nematodes were extracted from the sediment by gently stirring the sand and pouring the supernatant seawater through a $212 \mu \mathrm{m}$ mesh sieve. The retained meiofauna was collected in a petri dish, and single worms of similar size (1-2 mm length, representing adult L. oneistus) were handpicked by forceps (Dumont 3, Fine Science Tools, Canada) under a dissecting microscope. $L$. oneistus nematodes were identified based on morphological characteristics (31). Approximately $4 \mathrm{~h}$ after collection, the nematodes were used for various incubations as described below. Replicate incubations were started simultaneously. The spatial distribution of $L$. oneistus as well as concentrations of sulfide $\left(\sum \mathrm{H}_{2} \mathrm{~S}\right.$, i.e. the sum of $\mathrm{H}_{2} \mathrm{~S}, \mathrm{HS}^{-}$and $\mathrm{S}^{2-}$ ), dissolved inorganic nitrogen (DIN: nitrate, nitrite, and 
ammonia) and dissolved organic carbon (DOC) were determined in sediment cores at various depths (Supplementary Materials \& Methods, Figure S1A, and Table S1).

\section{Incubations for RNA sequencing (RNA-Seq)}

Batches of $50 \mathrm{~L}$. oneistus individuals per incubation and replicate were collected and incubated at two field trips. They were incubated for $24 \mathrm{~h}$ in the dark, in either the presence (oxic) or absence (anoxic) of oxygen, in 13 ml-exetainers (Labco, Lampeter, Wales, UK) fully filled with $0.2 \mu \mathrm{m}$ filtered seawater (Figure S1B). The oxic incubations consisted of two separate experiments of low (hypoxic; three replicates in July 2017) and high (oxic; three replicates in July 2017, three replicates in March 2019) oxygen concentrations. Here, all exetainers were kept open, but only the samples with high oxygen concentrations were submerged in an aquarium constantly bubbled with air (air pump plus; Sera, Heinsberg, Germany). Oxic incubations started with around $195 \mu \mathrm{M}$ of $\mathrm{O}_{2}$ and reached an average of $188 \mu \mathrm{M}$ after $24 \mathrm{~h}$. Hypoxic incubations started with around $115 \mu \mathrm{M} \mathrm{O}_{2}$ but reached less than $60 \mu \mathrm{M} \mathrm{O}_{2}$ after $24 \mathrm{~h}$. This likely occurred due to nematode oxygen consumption. On the other hand, the anoxic treatments comprised incubations to which either $11 \mu \mathrm{M}$ of sodium sulfide $\left(\mathrm{Na}_{2} \mathrm{~S}^{*} 9 \mathrm{H}_{2} \mathrm{O}\right.$; Sigma-Aldrich, St. Louis, MS, USA) was added (anoxic-sulfidic; three replicates in July 2017), or no sulfide was supplied (anoxic; three replicates in July 2017, two replicates in March 2019) (Figure $\mathrm{S} 1 \mathrm{~B})$, and $\sum \mathrm{H}_{2} \mathrm{~S}$ concentrations were checked at the beginning and at the end (24 h) of each incubation by spectrophotometric determination following the protocol of Cline (Supplementary Materials \& Methods). Anoxic incubations were achieved with the aid of a polyethylene glove bag (AtmosBag; Sigma-Aldrich) that was flushed with $\mathrm{N}_{2}$ gas (Fabrigas, Belize City, Belize), together with incubation media and all vials, for at least 1 $\mathrm{h}$ before closing. Dissolved oxygen inside the bag, and of every incubation was monitored throughout the $24 \mathrm{~h}$ incubation time using a PreSens Fibox 3 trace fiber-optic 
oxygen meter and non-invasive trace oxygen sensor spots attached to the exetainers (PSt6 and PSt3; PreSens, Regensburg, Germany). For exact measurements of $\sum \mathrm{H}_{2} \mathrm{~S}$ and oxygen see Table S2. The seawater used for all incubations had an initial concentration of nitrate and nitrite of $4.2 \mu \mathrm{M}$ and $0.31 \mu \mathrm{M}$, respectively (Supplementary Materials \& Methods). Temperature and salinity remained constant throughout all incubations measuring $27-28^{\circ} \mathrm{C}$ and $33-34 \%$, respectively. After the $24 \mathrm{~h}$ incubations, each set of 50 worms was quickly transferred into $2 \mathrm{ml}$ RNA storage solution (13.3 mM EDTA disodium dihydrate $\mathrm{pH} 8.0,16.6 \mathrm{mM}$ sodium citrate dihydrate, $3.5 \mathrm{M}$ ammonium sulfate, $\mathrm{pH} 5.2$ ), kept at $4^{\circ} \mathrm{C}$ overnight, and finally stored in liquid nitrogen until RNA extraction.

\section{RNA extraction, library preparation and RNA-Seq}

RNA from symbiotic L. oneistus was extracted using the NucleoSpin RNA XS Kit (Macherey-Nagel, Düren, Germany). Briefly, sets of 50 worms in RNA storage solution were thawed and the worms were transferred into $90 \mu$ lysis buffer RA1 containing Tris (2-carboxyethyl) phosphine (TCEP) according to the manufacturer's instructions. The remaining RNA storage solution was centrifuged to collect any detached bacterial cells (10 min, $4^{\circ} \mathrm{C}, 16100 \times \mathrm{g}$ ), pellets were resuspended in $10 \mu$ lysis buffer RA1 (plus TCEP) and then added to the worms in lysis buffer. To further disrupt cells, suspensions were vortexed for two minutes followed by three cycles of freeze $\left(-80^{\circ} \mathrm{C}\right)$ and thaw $\left(37^{\circ} \mathrm{C}\right)$, and homogenization using a pellet pestle (Sigma-Aldrich) for $60 \mathrm{~s}$ with a $15 \mathrm{~s}$ break after $30 \mathrm{~s}$. Any remaining biological material on the pestle tips was collected by rinsing the tip with $100 \mu$ lysis buffer RA1 (plus TCEP). Lysates were applied to NucleoSpin Filters and samples were processed according to the manufacturer's instructions, including an on-filter DNA digest. RNA was eluted in $20 \mu \mathrm{l}$ RNase-free water. To remove any residual DNA, a second DNase treatment was performed using the Turbo DNA-free Kit (Thermo 
Fisher Scientific, Waltham, MA, USA), RNA was then dissolved in $17 \mu \mathrm{l}$ RNase-free water, and the RNA quality was assessed using a Bioanalyzer (Agilent, Santa Clara, CA, USA). To check whether all DNA was digested, real-time quantitative PCR using the GoTaq qPCR Master Mix (Promega, Madison, WI, USA) was performed targeting a 158 bp stretch of the $\operatorname{sod} B$ gene using primers specific for the symbiont (sodB-F: GTGAAGGGTAAGGACGGTTC, sodB-R: AATCCCAGTTGACGATCTCC, $10 \mu \mathrm{M}$ per primer). Different concentrations of genomic Ca. T. oneisti DNA were used as positive controls. The program was as follows: $1 \times 95^{\circ} \mathrm{C}$ for $2 \mathrm{~min}, 40 \times 95^{\circ} \mathrm{C}$ for $15 \mathrm{~s}$ and $60^{\circ} \mathrm{C}$ for $1 \mathrm{~min}, 1 \times 95^{\circ} \mathrm{C}$ for $15 \mathrm{~s}, 55^{\circ} \mathrm{C}$ to $95^{\circ} \mathrm{C}$ for $20 \mathrm{~min}$. Next, bacterial and eukaryotic rRNA was removed using the Ribo-Zero Gold rRNA Removal Kit (Epidemiology) (Illumina, San Diego, CA, USA) following the manufacturer's instructions, but volumes were adjusted for low input RNA (32). In short, $125 \mu \mathrm{l}$ of Magnetic Beads Solution, $32.5 \mu \mathrm{l}$ Magnetic Bead Resuspension Solution, $2 \mu \mathrm{l}$ Ribo-Zero Reaction Buffer and $4 \mu \mathrm{l}$ Ribo-Zero Removal Solution were used per sample. RNA was cleaned up via ethanol precipitation, dissolved in $9 \mu \mathrm{l}$ RNase-free water, and rRNA removal was evaluated using the Bioanalyzer RNA Pico Kit (Agilent, Santa Clara, CA, USA). Strand-specific, indexed cDNA libraries were prepared using the SMARTer Stranded RNA-Seq Kit (Takara Bio USA, Mountain View, CA, USA). Library preparation was performed according to the instructions, with $8 \mu \mathrm{l}$ of RNA per sample as input, 3 min fragmentation time, two rounds of AMPure XP Beads (Beckman Coulter, Brea, CA, USA) clean-up before amplification, and 18 PCR cycles for library amplification. The quality of the libraries was assessed via the Bioanalyzer DNA High Sensitivity Kit (Agilent). Libraries were sequenced on an Illumina HiSeq 2500 instrument (single-read, $100 \mathrm{nt}$ ) at the next-generation sequencing facility of the Vienna BioCenter Core Facilities (VBCF, 


\section{Genome sequencing, assembly and functional annotation}

250

251

252

253

254

255

The genome draft of $\mathrm{Ca}$. T. oneisti was obtained by performing a hybrid assembly using reads from Oxford Nanopore Technologies (ONT) sequencing and Illumina sequencing. To extract DNA for ONT sequencing and dissociate the ectosymbionts from the host, approximately 800 Laxus oneistus individuals were incubated three times for 5 min each in TE-Buffer (10 mM Tris-HCl pH 8.0, $1 \mathrm{mM}$ disodium EDTA pH 8.0). Dissociated symbionts were collected by 10 min centrifugation at $7000 \times \mathrm{g}$ and subsequent removal of the supernatant. DNA was extracted from this pellet using the Blood and Tissue Kit (Qiagen, Hilden, Germany) according to the manufacturer's instructions. The eluant was further purified using the DNA Clean \& Concentrator-5 kit (Zymo Research, Irvine, CA, USA), and the DNA was eluted twice with $10 \mu$ nuclease-free water.

The library for ONT sequencing was prepared using the ONT Rapid Sequencing kit (SQK-RAD002) and sequenced on an R9.4 flow cell (FLO-MIN106) on a MinION for $48 \mathrm{~h}$. Base calling was performed locally with ONT's Metrichor Agent v1.4.2, and resulting fastq-files were trimmed using Porechop v0.2.1 (https://github.com/rrwick/Porechop). Illumina sequencing reads from a previous study (6), were made available by Harald Gruber-Vodicka (MPI Bremen). Raw reads were filtered: adapters removed and trimmed using bbduk (BBMap v37.22, https://sourceforge.net/projects/bbmap/), with a minimum length of 36 and a minimum phred score of 2. To only keep reads derived from the symbiont, trimmed reads were mapped onto the available genome draft (NCBI Accession FLUZ00000000.1) using BWA-mem v0.7.16a-r1181 (33). Reads that did not map were discarded. The hybrid assembly was performed using SPAdes v3.11 (34) with flags --careful and the ONT reads supplied as --nanopore. Contigs smaller than 200 bp and a coverage lower than 5X were filtered out with a custom python script. The genome completeness was 
assessed using CheckM v1.0.18 (35) with the gammaproteobacterial marker gene set using the taxonomy workflow. The genome was estimated to be $96.63 \%$ complete, contain $1.12 \%$ contamination, and was $4.35 \mathrm{Mb}$ in length on 401 contigs with a GC content of $58.7 \%$ and $\mathrm{N} 50$ value of $27,060 \mathrm{bp}$.

The genome of $\mathrm{Ca}$. T. oneisti was annotated using the MicroScope platform (36), which predicted 5169 protein-coding genes. To expand the functional annotation provided by MicroScope, predicted proteins were assigned to KEGG pathway maps using BlastKOALA and KEGG Mapper-Reconstruct Pathway (37), gene ontology (GO) terms using Blast2GO v5 (38) and searched for Pfam domains using the hmmscan algorithm of HMMER $3.0(39,40)$. All proteins and pathways mentioned in the manuscript were manually curated. Functional annotations can be found in Data S1.

\section{Gene expression analyses}

Based on quality assessment of raw sequencing reads using FastQC v0.11.8 (41) and prinseq-lite v0.20.4 (42), reads were trimmed and filtered using Trimmomatic v0.39 (43) and prinseq-lite as follows: 18 nucleotides were removed from the 5-prime end (HEADCROP), Illumina adapters were removed (ILLUMINACLIP:TruSeq3SE.fa:2:30:10), reads were trimmed when the average quality of a five-base sliding window dropped below a phred score of 20 (SLIDINGWINDOW:5:20), 3-prime poly-A tails were trimmed (-trim_tail_right 1), and only reads longer than 24 nucleotides were kept (MINLEN:25). Mapping and expression analysis were done as previously described (44). Briefly, reads were mapped to the Ca. T. oneisti genome draft using BWAbacktrack (33) with default settings, only uniquely mapped reads were kept using SAMtools (45), and the number of strand-specific reads per gene was counted using HTSeq in the union mode of counting overlaps (46). On average, $1.4 \times 10^{6}(4.4 \%)$ reads 
uniquely mapped to the $\mathrm{Ca}$. T. oneisti genome. For detailed read and mapping statistics see Figure S2A.

Gene and differential expression analyses were conducted using the $\mathrm{R}$ software environment and the Bioconductor package edgeR v3.28.1 (47-49). Genes were considered expressed if at least two reads in at least two replicates of one of the four conditions could be assigned. Including all four conditions, we found $92.8 \%$ of all predicted symbiont protein-encoding genes to be expressed (4 797 genes out of 5169 , Data S1). Log $_{2}$ TPM (transcripts per kilobase million) values were calculated by logtransforming TPMs to which library size-adjusted, positive prior counts were added in order to avoid zero TPMs (edgeR function addPriorCount, prior.count=4). $\log _{2}$ TPM values were used to assess sample similarities via multidimensional scaling based on Euclidean distances (R Stats package) (49) (Figure S2B), and the average of replicate $\log _{2}$ TPM values per expressed gene and condition was used to estimate expression strength. Median gene expression of entire metabolic processes and pathways per condition was determined from average $\log _{2}$ TPMs. A Wilcoxon signed-rank Test was applied to test for significantly different median gene expression between metabolic processes and pathways (R Stats package).

For differential expression analysis, raw data were normalized by the trimmed mean of M-values (TMM) normalization method (edgeR function calcNormFactors) (50), and gene-specific biological variation was estimated (edgeR function estimateDisp). Differential expression was determined using the quasi-likelihood F-test (edgeR functions glmQLFit and glmQLFTest) for pairwise comparisons (between all four conditions) and comparing both anoxic conditions against the average of both oxic conditions. Expression of genes was considered significantly different if their expression changed two-fold between two treatments with a false-discovery rate $(F D R) \leq 0.05$ (51). 
Throughout the paper, all genes meeting these thresholds are either termed differentially expressed or up- or downregulated. However, most follow-up analyses were conducted only considering differentially expressed genes between the anoxic-sulfidic (AS) condition and both oxygenated conditions combined (O, see Results and Figure S2C). For the differential expression analyses between all four conditions see Data S1. Heatmaps show mean-centered expression values to highlight gene expression change.

Bulk $\delta^{13} \mathrm{C}$ isotopic analysis by Isoprime isotope ratio mass spectrometry (EAIRMS)

To further analyze the carbon metabolism of $\mathrm{Ca}$. T. oneisti, specifically the assimilation of carbon dioxide $\left(\mathrm{CO}_{2}\right)$ by the symbionts in the presence or absence of oxygen, batches of 50 freshly collected, live worms were incubated for $24 \mathrm{~h}$ in $150 \mathrm{ml}$ of $0.2 \mu \mathrm{m}$-filtered seawater, supplemented with $2 \mathrm{mM}$ (final concentration) of either ${ }^{12} \mathrm{C}$ - (natural isotope abundance control) or ${ }^{13} \mathrm{C}$-labeled sodium bicarbonate (Sigma-Aldrich, St. Louis, MS, USA). In addition, a second control was set up (dead control), in which prior to the $24 \mathrm{~h}$ incubation with ${ }^{13} \mathrm{C}$-labeled sodium bicarbonate, 50 freshly collected worms were sacrificed by incubating them in a $2 \%$ paraformaldehyde/water solution for $12 \mathrm{~h}$.

All three incubations were performed in biological triplicates or quadruplets and set up under anoxic-sulfidic and oxic conditions. Like the RNA-Seq experiment, the oxic incubations consisted of two separate experiments of low (hypoxic) and high (oxic) oxygen concentrations. To prevent isotope dilution through exchange with the atmosphere, both the oxic and anoxic incubations remained closed throughout the $24 \mathrm{~h}$. The procedure was as follows: $0.2 \mu \mathrm{m}$-filtered anoxic seawater was prepared as described above and was subsequently used for both oxic and anoxic incubations. Then, compressed air (DAN oxygen kit, Divers Alert Network, USA) and $25 \mu \mathrm{M}$ of sodium sulfide $\left(\mathrm{Na}_{2} \mathrm{~S}^{*} 9 \mathrm{H}_{2} \mathrm{O}\right.$; Sigma-Aldrich, St. Louis, MS, USA) were injected into the oxic and 
anoxic incubations, respectively, to obtain concentrations resembling the conditions applied in incubations for the RNA-Seq experiment (see Table S2 for details about the incubation conditions and a compilation of the measurement data).

At the end of each incubation $(24 \mathrm{~h})$, the nematodes were weighed $(0.3-0.7 \mathrm{mg}$ dry weight) into tin capsules (Elemental Microanalysis, Devon, United Kingdom) and dried at $70^{\circ} \mathrm{C}$ for at least $24 \mathrm{~h}$. Samples were analyzed using a Costech (Valencia, CA USA) elemental analyzer interfaced with a continuous flow Micromass (Manchester, UK) Isoprime isotope ratio mass spectrometer (EA-IRMS) for determination of ${ }^{13} \mathrm{C} /{ }^{12} \mathrm{C}$ isotope ratios. Measurement values are displayed in $\delta$ notation (per mil $(\%))$. A protein hydrolysate, calibrated against NIST reference materials, was used as a standard in sample runs. The achieved precision for $\delta^{13} \mathrm{C}$ was $\pm 0.2 \%$ (one standard deviation of 10 replicate measurements on the standard).

\section{Raman microspectroscopy}

Three individual nematodes per EA-IRMS incubation were fixed and stored in $0.1 \mathrm{M}$ Trump's fixative solution (0.1 M sodium cacodylate buffer, $2.5 \%$ GA, 2\% PFA, pH 7.2, 1 $000 \mathrm{mOsm} \mathrm{L}^{-1}$ ) (52), and washed three times for $10 \mathrm{~min}$ in 1x PBS (137 mM NaCl, 2.7 $\mathrm{mM} \mathrm{KCl}, 10 \mathrm{mM} \mathrm{Na}_{2} \mathrm{HPO}_{4}, 1.8 \mathrm{mM} \mathrm{KH}_{2} \mathrm{PO}_{4}, \mathrm{pH}$ 7.4) before their ectosymbionts were dissociated by sonication for $40 \mathrm{~s}$ in $10 \mu \mathrm{l}$ x PBS. $1 \mu$ l of each bacterial suspension was spotted on an aluminum-coated glass slide and measured with a LabRAM HR Evolution Raman microspectroscope (Horiba, Kyoto, Japan). 50 individual single-cell spectra were measured from each sample. All spectra were aligned by the phenylalanine peak, baselined using the Sensitive Nonlinear Iterative Peak (SNIP) algorithm of the $\mathrm{R}$ package "Peaks" (https://www.rdocumentation.org/packages/Peaks/versions/0.2), and normalized by total spectrum intensity. For calculating the relative sulfur content, the average intensity value for $212-229$ wavenumbers ( $S_{8}$ peak) was divided by the average 
intensity of the adjacent flat region of 231-248 wavenumbers (19). For calculating the relative polyhydroxyalkanoate (PHA) content, the average intensity value for $1723-1$ 758 wavenumbers (PHA peak) was divided by the average intensity of the adjacent flat region of 1 759-1 793 wavenumbers (53). Median relative sulfur and PHA content (shown as relative Raman intensities) were calculated treating all individual symbiont cells per condition as replicates. Statistically significant differences were determined by applying the non-parametric Kruskal Wallis test, followed by pairwise comparisons.

\section{Assessment of the percentage of dividing cells}

Samples were fixed and ectosymbionts were dissociated from their hosts as described above for Raman microspectroscopy. $1.5 \mu$ of each bacterial suspension per condition were applied to a $1 \%$ agarose covered slide (54) and cells were imaged using a Nikon Eclipse NI-U microscope equipped with an MFCool camera (Jenoptik). Images were obtained using the ProgRes Capture Pro 2.8.8 software (Jenoptik) and processed with ImageJ (55). Bacterial cells were manually counted (> 600 per sample) and grouped into constricted (dividing) and non-constricted (non-dividing) cells based on visual inspection (27). The percentage of dividing cells was calculated by counting the total number of dividing cells and the total amount of cells per condition. Statistical tests were performed using Fisher's exact test.

Data availability. The assembled and annotated genome of $\mathrm{Ca}$. T. oneisti has been deposited at DDBJ/ENA/GenBank under the accession JAAEFD000000000. RNA-Seq data are available at the Gene Expression Omnibus (GEO) database and are accessible through accession number GSE146081.

\section{RESULTS}

\section{Hypoxic and oxic conditions induce similar expression profiles}


To understand how the movement of the animal host across the chemocline affects symbiont physiology and metabolism, we exposed symbiotic worms to sulfide (thereafter used for $\sum \mathrm{H}_{2} \mathrm{~S}$ ) and oxygen concentrations resembling the ones encountered by $\mathrm{Ca}$. $\mathrm{T}$. oneisti in its natural habitat. Previous studies showed that Stilbonematinae live predominantly in anoxic sediment zones with sulfide concentrations $<50 \mu \mathrm{M}$ (12). To assess whether this applies to Laxus oneistus (i.e. Ca. T. oneisti's host) at our collection site (Carrie Bow Cay, Belize), we determined the nematode abundance relative to the sampling depth and sulfide concentration. We found all $L$. oneistus individuals in pore water containing $\leq 25 \mu \mathrm{M}$ sulfide and only $1.3 \%$ of them living in non-sulfidic $(0 \mu \mathrm{M}$ sulfide) surface layers (Figure S1A, Table S1). Therefore, we chose anoxic seawater supplemented with $\leq 25 \mu \mathrm{M}$ sulfide as the incubation medium (AS condition). To assess the effect of oxygen on symbiont physiology, we additionally incubated the nematodes in hypoxic ( $<60 \mu \mathrm{M}$ oxygen after $24 \mathrm{~h})$ and oxic ( $>100 \mu \mathrm{M}$ after $24 \mathrm{~h})$ seawater. Nitrate, nitrite, ammonium and DOC could be detected throughout the sediment core including the surface layer (Figure S1A, Table S1).

Differential gene expression analysis comparing hypoxic and oxic incubations revealed that only $2.9 \%$ of all expressed protein-coding genes differed significantly in their expression. Crucially, this gene set comprised several hypothetical proteins but did not show any significantly enriched metabolic pathways, processes or protein families (Figure S2, Table S3, Data S1). Because the presence of oxygen, irrespective of its concentration, resulted in a similar metabolic response, we treated the samples derived from hypoxic and oxic incubations as biological replicates, and we will hereafter refer to them as the $\mathrm{O}$ condition.

Differential gene expression analysis between the AS and $\mathrm{O}$ conditions revealed that $20.7 \%$ of all expressed protein-coding genes exhibited significantly different 
expression between these two conditions (Figure S2C), and we will present their expression analysis below.

\section{Sulfur oxidation genes are upregulated in anoxia}

Ca. T. oneisti genes encoding for a sulfur oxidation pathway similar to that of the related but free-living purple sulfur bacterium Allochromatium vinosum (Figure S3) were highly expressed in both AS and O conditions compared with other central metabolic processes, albeit median gene expression was significantly higher under the AS condition (Figure 1). Consistently, 24 out of the 26 differentially expressed genes involved in sulfur oxidation, were upregulated under AS (Figure 2A). These mostly included genes involved in the cytoplasmic branch of sulfur oxidation, i.e. genes associated with sulfur transfer from sulfur storage globules (rhd, tusA, dsrE2), genes encoding for the reverse-acting $d s r$ (dissimilatory sulfite reductase) system involved in the oxidation of stored elemental sulfur $\left(\mathrm{S}^{0}\right)$ to sulfite and, finally, also the genes required for further oxidation of sulfite to sulfate in the cytoplasm by two sets of adenylylsulfate (APS) reductase (aprAB) along with their membrane anchor (aprM) and sulfate adenylyltransferase (sat) (56). Genes encoding a quinone-interacting membrane-bound oxidoreductase $(q m \circ A B C)$ exhibited the same expression pattern. This is noteworthy, as AprM and QmoABC are hypothesized to have an analogous function, and their cooccurrence is rare among sulfur-oxidizing bacteria $(56,57)$.

Concerning genes involved in the periplasmic branch of sulfur oxidation such as the two types of sulfide-quinone reductases ( $s q r A$, sqrF; oxidation of sulfide), the Sox system (soxKAXB, soxYZ) and the thiosulfate dehydrogenase (tsdA) both involved in the oxidation of thiosulfate, transcript levels were unchanged between both conditions (Data S1). Only the flavoprotein subunit of the periplasmic flavocytochrome c sulfide 
dehydrogenase $(f c c B)$ as well as a cytochrome $c$ family protein $(t s d B)$ thought to cooperate with TsdA, were downregulated in the absence of oxygen (Figure 2A).

To assess whether the upregulation of sulfur oxidation genes under anoxia was due to the absence of oxygen (and not to the presence of supplemented sulfide in the medium), we performed an additional anoxic incubation where sulfide was not provided (A condition). Differential expression analysis between the anoxic conditions with and without sulfide revealed that transcript levels of $6.3 \%$ of all expressed protein-coding genes differed significantly between the two anoxic treatments (Figure S2C). Among them, we found eight genes involved in sulfur oxidation to be upregulated in the presence of sulfide (Data S1). Importantly, however, irrespective of sulfide supplementation, most sulfur oxidation genes were similarly upregulated relative to the $\mathrm{O}$ incubation (Figure S4A, Table S3). In addition, proteome data derived from incubations with and without oxygen, but no added sulfide, showed that one copy of AprA and AprM were among the top expressed proteins under anoxia (Table S4, Supplementary Materials \& Methods). Raman microspectroscopy revealed that levels of elemental stored sulfur $\left(\mathrm{S}^{0}\right)$ were highest under AS and hypoxic conditions and low or below detection limit under oxic and anoxic without sulfide conditions at the end of the incubations (Figure S4B).

Collectively, sulfur oxidation genes were upregulated under both anoxic conditions irrespective of sulfur storage content and were, conversely, downregulated under hypoxic conditions in spite of elemental sulfur availability in most of the symbiont cells.

\section{Upregulation of anaerobic respiratory enzymes under AS conditions}

Given that sulfur oxidation was upregulated under anoxic conditions, we expected this process to be coupled to the reduction of anaerobic electron acceptors, and nitrate respiration has been shown for symbiotic L. oneistus (13). Consistently, genes encoding 
472 for components of the four specific enzyme complexes active in denitrification (nap, nir,

473 nor, nos), as well as two subunits of the respiratory chain complex III (petA and petB of

474 the cytochrome bc1 complex, which is known for being involved in denitrification and in

475 the aerobic respiratory chain; 58) were upregulated under AS conditions (Figures 2A 476 and S5).

Besides nitrate respiration, Ca. T. oneisti may also utilize polysulfide or thiosulfate as terminal electron acceptors under AS conditions, since we observed an upregulation of all genes encoding either a respiratory polysulfide reductase or thiosulfate reductase (psrA/phsA, psrB/phsB, prsC/phsC; DMSO reductase family, classification based on 59).

Concerning other anaerobic electron acceptors, the symbiont has the genetic potential to carry out fumarate reduction ( $f r d A B C D$ genes, Figure $S 3$ ), and the fumarate reductase flavoprotein subunit ( $f r d A$ ) was indeed upregulated under AS conditions (Figure S5). We also identified a gene potentially responsible for the biosynthesis of rhodoquinone (rquA, Data S1, Figure S3), which acts as an electron carrier in anaerobic respiration in a few other prokaryotic and eukaryotic organisms $(60,61)$, and could thus replace the missing menaquinone during anaerobic respiration in $\mathrm{Ca}$. T. oneisti. as well as significantly higher relative abundances of several lyso-phospholipids under anoxia (Figure S6A, Supplementary Materials \& Methods), possibly resulting in altered uptake behavior and higher membrane permeability for electron donors and acceptors (62-65). Notably, we also detected lyso-phosphatidylcholine to be significantly more abundant in anoxia (Figure S6B). As the symbiont does not possess any known genes for biosynthesis of this lipid, it may be host-derived. Incorporation of host lipids into symbiont membranes was reported previously $(66,67)$. 

dehydrogenase gene ( $g / p D$, Figure S5), as well as the substrate-binding subunit of a

498

499

500

501

502

503

504

505

506

507

508

509

510

511

512

513

514

515

516

517

518

putative G3P transporter gene (ugpABCD genes, Data S1), suggests that putatively host lipid-derived G3P serves as carbon and energy source for the symbiont under anoxia.

Taken together, our data indicate that under AS conditions, the ectosymbiont gains energy by coupling sulfur oxidation to the complete reduction of nitrate to dinitrogen gas. Moreover, the symbiont appears to exploit oxygen-depleted environments for energy generation by utilizing G3P as an additional electron donor, and nitrate, polysulfide or thiosulfate, and fumarate as electron acceptors.

\section{Upregulation of sulfur oxidation genes is not accompanied by increased}

\section{expression of carbon fixation genes}

Several thioautotrophic symbionts have been shown to use the energy generated by sulfur oxidation for the fixation of inorganic carbon $(7,18,19,68-70)$. Previous studies strongly support that $\mathrm{Ca}$. T. oneisti is capable of fixing carbon via an energy-efficient Calvin-Benson-Bassham (CBB) cycle (6, 10, 11, 29, , 71) (Figure S3). In this study, bulk isotope-ratio mass spectrometry (IRMS) conducted with symbiotic nematodes confirmed that they incorporate isotopically-labeled inorganic carbon, and we detected no significant difference in incorporation between any two incubations in the course of $24 \mathrm{~h}$ (Figure 2B). To localize the sites of carbon incorporation, we subjected symbiotic nematodes incubated with ${ }^{13} \mathrm{C}$-bicarbonate to nanoscale secondary ion mass spectrometry (NanoSIMS) and detected ${ }^{13} \mathrm{C}$ enrichment predominantly within the ectosymbiont (Figure S7, Supplementary Materials \& Methods).

Consistent with the evidence for carbon fixation by the ectosymbiont, all genes related to the $\mathrm{CBB}$ cycle were detected, both on the transcriptome and the proteome level, with high transcript levels under both AS and O conditions (Figure 1, Data S1). 
521 However, the upregulation of sulfur oxidation genes observed under AS did not coincide

522 with an upregulation of carbon fixation genes. On the contrary, the median expression

523 level of all CBB cycle genes was significantly higher in the presence of oxygen (Figure

524 1). In particular, the transcripts encoding for the small subunit of the key autotrophic

525 carbon fixation enzyme ribulose-1,5-bisphosphate carboxylase/oxygenase RuBisCO

$526(c b b S)$ together with the transcripts encoding its activases ( $c b b Q$ and $c b b O ; 72)$, the

527 PPi-dependent 6-phosphofructokinase (PPi-PFK; 73, 74) and the neighboring PPi-

528 energized proton pump ( $h p p A)$ thought to be involved in energy conservation during

529 autotrophic carbon fixation $(73,74)$ were upregulated under $\mathrm{O}$ conditions (Figure 2A).

530 The large subunit of the RuBisCO protein (CbbL, type I-A group, Figure S8) was among

531 the top expressed proteins under anoxic and oxic conditions (Table S4). inorganic carbon was detected to a similar extent in the presence and absence of oxygen.

Genes involved in the utilization of organic carbon and PHA storage build-up are

\section{upregulated in the presence of oxygen}

As anticipated, the nematode ectosymbiont may exploit additional reduced compounds besides sulfide for energy generation. Indeed, Ca. T. oneisti possesses the genomic

540 potential to assimilate glyoxylate, acetate and propionate via the partial 3hydroxypropionate cycle (like the closely related Olavius algarvensis y1-symbiont; 73), and furthermore encodes genes for utilizing additional small organic carbon compounds such as G3P, glycolate, ethanol and lactate (Figure S3, Data S1). With the exception of

544 G3P utilization genes (see above), the expression of genes involved in the assimilation 545 of organic carbon including their putative transporters was significantly higher under $\mathrm{O}$ 
conditions (Figure 1). Among the upregulated genes were lutB (involved in the oxidation

547 of lactate to pyruvate; 75), propionyl-CoA synthetase (prpE, propanoate assimilation; 76)

548 and two components of a TRAP transporter which most commonly transports 549 carboxylates (77) (Data S1).

$550 \quad$ These gene expression data imply that the nematode ectosymbiont uses organic 551 carbon compounds in addition to $\mathrm{CO}_{2}$ under $\mathrm{O}$ conditions, thereby increasing the supply 552 of carbon. Consistent with high carbon availability, genes necessary to synthesize

553

554

555

556

557

558

559

560

561

562

563

564

565

566

567

568

569

570 storage compounds such as polyhydroxyalkanoates (PHA), glycogen and trehalose showed an overall higher median transcript level under $\mathrm{O}$ conditions (Figure 1 ). In particular, two key genes involved in the biosynthesis of the PHA compound polyhydroxybutyrate (PHB) - acetyl-CoA acetyltransferase (phaA) and a class III PHA synthase subunit (phaC-2) - were upregulated in the presence of oxygen. Conversely, we observed upregulation of both PHB depolymerases involved in PHB degradation under AS, and Raman microspectroscopy showed that the median PHA content was slightly lower in symbiont cells under AS relative to both oxic conditions after the incubation period (Figure S9).

We propose that in the presence of oxygen, enhanced mixotrophy (i.e., simultaneous assimilation of inorganic and organic carbon) would result in higher carbon availability reflected by PHA storage build-up and facilitating facultative chemolithoautotrophic synthesis of ATP via the aerobic respiratory chain.

\section{Upregulation of nitrogen assimilation in the presence of oxygen}

It has been shown that high carbon availability is accompanied by high nitrogen assimilation (78-80). Indeed, despite the sensitivity of nitrogenase toward oxygen (81), its key catalytic MoFe enzymes (nifD, nifK; 82) and several other genes involved in nitrogen fixation were drastically upregulated in the presence of oxygen (Figures 1 and 
571

572

573

574

575

576

577

578

579

580

581

582

583

584

585

586

587

588

589

590

591

592

593

594

595

3). Moreover, in accordance with a recent study showing the importance of sulfur assimilation for nitrogen fixation (83), genes involved in the assimilation of sulfate, i.e. the sulfate transporters sulP and cysZ as well as genes encoding two enzymes responsible for cysteine biosynthesis (cysM, cysE) were also upregulated in the presence of oxygen (Data S1).

Besides nitrogen fixation, genes involved in urea uptake (transporters, urtCBDE) and utilization (urease, ure $F$ and $u r e G$ ) were also significantly higher transcribed under O conditions (Figures 1 and 3).

In conclusion, genes involved in nitrogen assimilation (from $\mathrm{N}_{2}$ or urea) were consistently upregulated in the presence of oxygen, when (1) carbon assimilation was likely higher, and when (2) higher demand for nitrogen is expected due to stress-induced synthesis of vitamins (see section below).

Upregulation of biosynthesis of cofactors and vitamins and global stress response in the presence of oxygen

Multiple transcripts and proteins associated with diverse bacterial stress responses were among the top expressed in the presence of oxygen (Figure 1 and Table S4). More specifically, heat-shock proteins Hsp70 and Hsp90 were highly abundant (Table S4), and transcripts of heat-shock proteins (Hsp15, Hsp20, Hsp40 and Hsp90) were upregulated (Figure 4A). Besides chaperones, we also detected upregulation of a transcription factor which induces synthesis of Fe-S clusters under oxidative stress (iscR; 84) along with several other genes involved in Fe-S cluster formation (Figure 4B, 86), and regulators for redox homeostasis, like thioredoxins, glutaredoxins and peroxiredoxins (86). Furthermore, we observed upregulation of protease genes (lon, ftsH, rseP, htpX, hspQ; 88-92), genes required for repair of double-strand DNA breaks (such as $\operatorname{rad} A$, recB, mutSY, mfd; 93-95), and relA, known to initiate the stringent 
response when cells are starved for amino acids (95) (Figure 4A). Amino acid starvation could be caused by a high demand for stress-related proteins under $O$ conditions, and could also explain the upregulation of amino acid biosynthesis pathways under $O$ conditions (96) (Figure 1).

SspA, a gene shown to be important for survival under various stress conditions (97-99), was the only stress-related gene upregulated under AS (Figure 4A). We hypothesized that the drastic upregulation of stress-related genes observed under oxic conditions would entail an increase in the biosynthesis of vitamins (100-102). Indeed, genes involved in biosynthesis of vitamins such as vitamins $B_{2}, B_{6}, B_{9}$ and $B_{12}$ were upregulated in the presence of oxygen (Figures 1 and 4A). Notably, the proposed upregulation of nitrogen fixation and urea utilization (see previous section) would support the synthesis of these nitrogen-rich molecules.

The upregulation of stress-related genes under oxic conditions was accompanied by significantly fewer dividing symbiont cells, i.e. 19.2\% (under O conditions) versus $30.1 \%$ (under AS conditions) (Figure 4B) and downregulation of early (ftsE, fts $X$ ) and late (damX, fts $M$ ) cell division genes (103) (Figure 1, Data S1). Oxygen may therefore elicit a stress response that hampers symbiont proliferation.

\section{DISCUSSION}

This is the first study reporting on the global transcriptional response to oxygen of a thiotrophic animal ectosymbiont, $\mathrm{Ca}$. T. oneisti. To the best of our knowledge, the only comparable study is the one conducted on a vent snail endosymbiont subjected to different concentrations of reduced sulfur species (19). Here, we detected a strong transcriptional response of $\mathrm{Ca}$. T. oneisti key metabolic processes to oxygen, as well as shifts in protein abundance and lipid composition. Although ongoing comparative host 
621 transcriptomics suggests that nematode physiology responds to oxygen (L.K.,

622 unpublished data) and although host response likely affects that of $\mathrm{Ca}$. T. oneisti, this

623 study exclusively focused on the effect of oxygen on symbiont physiology.

\section{Experimental design}

The concentrations of oxygen and sulfide to which symbiotic nematodes were exposed in our study were chosen based on those measured in the sediment they inhabit at so-called "cool spots", i.e. sand areas where sulfide concentrations increase gradually with depth but are $<50 \mu \mathrm{M}$ (Figure S1 and 22). Given that in this sand oxygen and sulfide hardly co-occur $(104,105)$, we did not add any sulfide when nematodes were incubated in the presence of oxygen. While this is reflected in largely depleted symbiont sulfur stores after $24 \mathrm{~h}$ under the oxic condition, the symbiont's sulfur stores remained high under hypoxic and anoxic-sulfidic (AS) condition (Figure S4B). Although we would expect the presence or absence of stored sulfur to affect the symbiont's metabolism if no external sulfide is present, our data indicate that the gene expression profiles of the sulfur oxidation pathway and other central processes solely followed the presence and absence of oxygen irrespective of sulfide supplementation (Figures 2A and S4A). Residual pre-incubation sulfur stores and other reduced sulfur compounds, such as thiosulfate, present in the seawater may have rendered the symbiont resilient toward the absence of external sulfide.

\section{Anaerobic sulfur oxidation}

641 Genes involved in sulfur oxidation showed high overall expression compared to other central metabolic processes, indicating that thiotrophy is the predominant energygenerating process for Ca. T. oneisti in both oxic and anoxic conditions (Figure 5). Thus, our data strongly support previous observations of Stilbonematinae ectosymbionts 
646

647

648

649

650

651

652

653

654

655

656

657

658

659

660

661

662

663

664

665

666

667

668

669

670

involved in denitrification were upregulated under AS conditions (Figures 2A), nitrate likely serves as terminal electron acceptor for anaerobic sulfur oxidation. Importantly, we detected nitrate in the incubation medium, as well as in all sediment layers (Figure S1 A, Table S1) at concentrations typical of oligotrophic sediment, in which also the $O$. algarvensis $\mathrm{y}^{3}$-symbiont is predicted to couple sulfur oxidation to denitrification (73). Sulfur oxidation in chemosynthetic symbioses is commonly described as an aerobic process required for host survival (3). However, many of these symbiotic organisms likely experience periods of oxygen depletion as would be expected from life at the interface of oxidized and reduced marine environments. Together with previous reports demonstrating nitrate reduction (14-16) and studies showing the genomic potential for using nitrate as terminal electron acceptor $(6,73,106-108)$, this study substantiates that nitrate respiration during temporary anoxia could represent a more important strategy for energy conservation among thiotrophic symbionts than currently acknowledged.

While upregulation of sulfur oxidation and denitrification genes in anoxia represents no proof for preferential anaerobic sulfur oxidation, we hypothesize that oxidation of reduced sulfur compounds to sulfate is more pronounced when oxygen is absent. Among the upregulated sulfur oxidation genes, we identified aprM and the qmoABC complex, both of which are thought to act as electron-accepting units for APS reductase, and therefore rarely co-occur in thiotrophic bacteria (56). The presence and expression of the QmoABC complex could provide a substantial energetic advantage to the ectosymbiont by mediating electron bifurcation (56), in which the additional reduction of a low-potential electron acceptor (e.g. ferredoxin, $\mathrm{NAD}^{+}$) could result in optimized energy conservation under anoxic conditions. The maximization of sulfur oxidation under anoxia might even represent a temporary advantage for the host. Indeed, this would be 
671

672

673

674

675

676

677

678

679

680

681

682

683

684

685

686

687

688

689

690

691

692

693

694

shielded from sulfide poisoning while crawling in a sediment which is free of predators but rich in decomposed organic matter (detritus) $(13,109-111)$. Due to the dispensability of oxygen for sulfur oxidation, the ectosymbiont may not need to be shuttled to superficial sand by their nematode hosts to oxidize sulfur. Host migration into upper zones of the sediment may therefore primarily reflect the oxygen dependence of the animal host.

In addition to anaerobic sulfur oxidation, the nematode ectosymbiont's phylogenetic affiliation with facultative anaerobic, anoxygenic phototrophic sulfur oxidizers such as Allochromatium vinosum $(6,112)$, and the presence and expression of yet other anaerobic respiratory complexes (DMSO reductase family enzyme and fumarate reductase) collectively suggest that $\mathrm{Ca}$. T. oneisti might be well-adapted to anoxic-sulfidic sediment zones.

\section{Symbiont proliferation in anoxia}

Although a few studies shed light on the molecular cell biology of $\mathrm{Ca}$. T. oneisti reproduction $(25,27,113)$, up to this study, we did not know how this is influenced by environmental changes. Here, we observed significantly higher numbers of dividing cells under AS conditions (Figure 4B) and therefore, sulfur oxidation coupled to denitrification might represent the ectosymbiont's preferred strategy to generate energy for growth. We hypothesize that aside from sulfur oxidation, the mobilization of PHA could represent an additional source of ATP (and carbon) supporting symbiont proliferation under AS (Figure S9, Figure 5). Of note, PHA mobilization in anoxia was also shown for Beggiatoa spp. (114). On the other hand, several lines of research have shown that stress experienced by $\mathrm{Ca}$. T. oneisti in the presence of oxygen (Figure 4A) - can inhibit bacterial growth (115-121). Importantly, studies on growth preferences of thiotrophic symbionts are scarce, and increased proliferation of a thiotroph with anaerobic electron 
acceptors (such as nitrate) with respect to using oxygen has never been observed before (122-125).

\section{Loose coupling of sulfur oxidation and carbon fixation}

Reduced sulfur compounds stimulate carbon fixation in thioautotrophic symbionts $(7,11$, $18,19,68-70,126,127)$. Our bulk isotope-ratio mass spectrometry (EA-IRMS) analysis indicates that, even though expression of the sulfur oxidation pathway was stimulated (Figures 1 and 2), fixation of ${ }^{13} \mathrm{C}$-bicarbonate-derived carbon was not the highest under AS conditions. Instead, carbon fixation appeared unaffected by the presence/absence of oxygen.

Even though, based on EA-IRMS, oxygen did not affect carbon fixation, CBB cycle transcripts in general, and RuBisCO-associated transcripts in particular, were significantly more abundant when oxygen was present (Figures 1 and 2). Upregulation of these genes could be a mechanism to counteract an increased oxygenase activity of RuBisCO in the presence of oxygen, as competition between its two substrates $\left(\mathrm{CO}_{2}\right.$ and $\mathrm{O}_{2}$ ) has been reported to constrain the carbon fixation efficiency of the enzyme (128, 129). Phylogenetic analysis of the ectosymbiont RuBisCO large subunit protein (CbbL) placed it within the type I-A group (Figure S8), whose characterized representatives are adapted to oxic environments $(129,130)$. The discrepancy between carbon incorporation and transcriptome data could thus reflect a tradeoff between the carboxylase and oxygenase activity of RuBisCo. Of note, fixation of $\mathrm{CO}_{2}$ by other carboxylating enzymes may not significantly contribute to the observed pattern of inorganic carbon incorporation. Indeed, acetyl-CoA carboxylase (acc genes) is predicted to only act as a biosynthetic carboxylase, whereas the constitutively expressed propionyl-CoA carboxylase $(p c c B)$ takes part in the partial 3-hydroxypropionate cycle thought to mainly function in assimilation of organic substrates in some thiotrophic 
symbionts $(71,73,131)$. No other known carboxylases are found in the symbiont genome.

Altogether, both lines of evidence point toward a loose coupling between sulfur oxidation and autotrophic carbon fixation. Notably, sulfide oxidation without matching $\mathrm{CO}_{2}$ fixation has been described before for the symbiont of Riftia pachyptila $(132,133)$ and an example of extreme decoupling of sulfur oxidation and carbon fixation was recently reported for Kentrophoros ectosymbionts. Strikingly, these lack genes for autotrophic carbon fixation altogether and thus represent the first heterotrophic sulfuroxidizing symbionts (71).

\section{Oxic mixotrophy}

Several chemosynthetic symbionts may engage in mixotrophy $(6,19,73,74,134)$, and also the nematode ectosymbiont possesses genes for transport of small organic carbon compounds, their assimilation and further metabolization (TCA cycle, glyoxylate shunt). Some of the organic carbon compounds represent typical host waste products (acetate, lactate, propionate) and could therefore be host-derived (73).

The expression of genes involved in transport and assimilation pathways was significantly more pronounced under $O$ than under AS conditions (Figure 1). In addition to assimilating inorganic carbon autotrophically, the ectosymbiont may thus assimilate more organic carbon in the presence of oxygen and, consequently, experience higher carbon availability (Figure 5).

While repression of RuBisCO biosynthesis by organic carbon has been demonstrated $(135,136)$, simultaneous incorporation of organic and inorganic carbon has been described for several facultative autotrophic bacteria (137-143). Concomitant mixotrophy is thought to be an advantage in oligotrophic environments where nutrients 
are limiting $(140,144)$, and $\mathrm{CO}_{2}$ derived from the breakdown of organic carbon through decarboxylation can subsequently be reutilized via the CBB cycle (141).

The metabolization of these organic carbon compounds ultimately yields acetylCoA, which, in turn, can be further oxidized in the TCA cycle and/or utilized for fatty acid and PHA biosynthesis (Figures S3 and 5). Our transcriptome and Raman microspectroscopy data suggest that $\mathrm{Ca}$. T. oneisti favors PHA build-up over its degradation under $\mathrm{O}$ conditions (Figure S9). Higher carbon availability in the presence of oxygen resulting in a surplus of acetyl-CoA may cause a nutrient imbalance that could facilitate PHA accumulation as previously shown (145-147). Moreover, it might play a role in resilience against cellular stress, as there is increasing evidence that PHA biosynthesis is enhanced under unfavorable growth conditions such as extreme temperatures, UV radiation, osmotic shock and oxidative stress (148-156). Similar findings have been obtained for pathogenic (157) and symbiotic bacteria of the genus Burkholderia (158), with the latter study reporting upregulation of stress response genes and PHA biosynthesis in the presence of oxygen. Finally, oxic biosynthesis of PHA might also prevent excessive accumulation and breakdown of sugars by glycolysis and oxidative phosphorylation, which, in turn, would exacerbate oxidative stress (159).

\section{Oxic nitrogen assimilation}

Despite the oxygen-sensitive nature of nitrogenase (81), we observed a drastic upregulation of nitrogen fixation genes under $\mathrm{O}$ conditions (Figures 1 and 3 ). Besides ammonia production, nitrogen fixation can act as an electron sink during heterotrophic conditions $(160,161)$. The ectosymbiont may therefore use the nitrogenase to maintain redox balance in the cell when organic carbon is metabolized under oxic conditions.

Urea utilization and uptake genes were also upregulated. Although the nematode host likely lacks the urea biosynthetic pathway (L.K., unpublished data), this compound is one 
of the most abundant organic nitrogen substrates in marine ecosystems, as well as in animal-inhabited (oxygenated) sand $(162,163)$. The apparent increase in nitrogen assimilation in the presence of oxygen could thus be a result of an increased demand for nitrogen driven by the biosynthesis of nitrogen-rich compounds such as vitamins and cofactors potentially required to survive oxidative stress (Figures 1, 4 and 5). Indeed, the upregulation of the urea uptake system and urease accessory proteins as well as the aforementioned stress-related relA gene has been shown to be a response to nitrogen limitation in other systems $(164,165)$; nitrogen imbalance may have also induced PHA accumulation under oxic conditions (145-147). The role of vitamins in protecting cells against the deleterious effects of oxygen has been shown for animals $(166,167)$, and the importance of riboflavin for bacterial survival under oxidative stress has previously been reported $(100,102)$. Along this line of thought, oxygen-exposed Ca. T. oneisti upregulated glutathione and thioredoxin, which are known to play a pivotal role in scavenging reactive oxygen species (ROS) (168). Their function directly (or indirectly) requires vitamin $B_{2}, B_{6}$ and $B_{12}$ as cofactors. More specifically, thioredoxin reductase (trxB) requires riboflavin (vitamin $B_{2}$ ) in the form of flavin adenine dinucleotide (FAD) (169); cysteine synthase (cysM) and glutamate synthases (two-subunit $g / t B / g / t D$, onesubunit $g / t S$ ) involved in the biosynthesis of the glutathione precursors L-cysteine and Lglutamate depend on vitamin $\mathrm{B}_{6}, \mathrm{FAD}$ and riboflavin in the form of flavin mononucleotide (FMN) $(170,171)$. As for cobalamin, it was thought that this vitamin only played an indirect role in oxidative stress resistance (172), by being a precursor of S-adenosyl methionine (SAM), a substrate involved in the synthesis of glutathione via the methionine metabolism (and the transulfuration pathway), and in preventing the Fenton reaction $(173,174)$. However, its direct involvement in the protection of chemolithoautotrophic bacteria against oxidative stress has also been illustrated (101). 
In summary, in the presence of oxygen, the upregulation of genes involved in

795

796

797

798

799

800

801

802

803

804

805

806

807

808

809

810

811

812

813

814

815

816

817

818

biosynthesis of vitamins $\mathrm{B}_{2}, \mathrm{~B}_{6}$ and $\mathrm{B}_{12}$ along with antioxidant systems and their key precursor genes cysM and $\mathrm{B}_{12}$-dependent-methionine synthase $m e t H$, suggests that the ectosymbiont requires increased levels of these vitamins to cope with oxidative stress (Figure 5).

\section{Evolutionary considerations}

Anaerobic sulfur oxidation, increased symbiont proliferation and downregulation of stress-related genes lead us to hypothesize that $\mathrm{Ca}$. T. oneisti evolved from a free-living bacterium that mostly, if not exclusively, inhabited anoxic sand zones. In support of this, the closest relatives of the nematode ectosymbionts are free-living sulfur oxidizers thriving under anoxic conditions (i.e. Allochromatium vinosum, Thioflavicoccus mobilis, Marichromatium purpuratum) $(6,175)$. Eventually, advantages such as protection from predators or utilization of host waste products (e.g. fermentation products, ammonia) may have been driving forces that led to the Ca. Thiosymbion-Stilbonematinae symbioses. As the association became more and more stable, the symbiont optimized (or acquired) mechanisms to resist oxidative stress, as well as metabolic pathways to most efficiently exploit the metabolic potential of oxygenated sand zones (mixotrophy, nitrogen assimilation, vitamin and cofactor biosynthesis). From the L. oneistus nematode perspective, the acquired "symbiotic skin" enabled it to tolerate the otherwise poisonous sulfide and to thrive in sand virtually devoid of predators, but rich in decomposed organic matter.

\section{ACKNOWLEDGEMENTS}

This work was supported by the Austrian Science Fund (FWF) grant P28743 (T. V., S. B. and L. K.) and the DK plus: Microbial Nitrogen Cycling (G. F. P.). We are indebted to 
Florian Goldenberg, Patrick Hyden and Thomas Rattei (Division of Computational oneisti at the University of Vienna. Harald Gruber-Vodicka from the MPI Bremen generously provided Illumina raw reads to aid the assemblies of ectosymbiont genomes.

We are very grateful to Wiebke Mohr, Nikolaus Leisch and Nicole Dubilier from the MPI for Marine Microbiology (Bremen) for continuous technical support with the stable isotope-based techniques. We appreciate Tjorven Hinzke's advice on metaproteome statistics and Carolina Reyes for her input on the nitrogen metabolism. We thank Yin Chen for providing the facilities for lipidomic analysis and Eleonora Silvano for assistance with lipid extractions, and Jana Matulla's and Sebastian Grund's excellent technical work during protein sample preparation and MS analysis, respectively. Also, our sincere gratitude to the Carrie Bow Cay Laboratory, Caribbean Coral Reef Ecosystem Program and Station Manager Zach Foltz for his continuous help during field work. Finally, we were very much helped and inspired by insightful discussions with Monika Bright, Jörg A. Ott, Christa Schleper, Simon K.-M.R. Rittmann, Filipa Sousa and Jillian Petersen.

\section{Competing Interests}

838 The authors declare no competing financial interest.

\section{REFERENCES}


phylogeny substantially revises the tree of life. Nat Biotechnol 36:996.

2. Ott J, Bright M, Bulgheresi S. 2004. Marine microbial thiotrophic ectosymbioses, p. 95-118. In Gibson, RN, Atkinson, RJA, Gordon, JDM (eds.), Oceanography and Marine Biology: An Annual Review, 42nd ed.

3. Dubilier N, Bergin C, Lott C. 2008. Symbiotic diversity in marine animals: the art of harnessing chemosynthesis. Nat Rev Microbiol 6:725-740.

4. Stewart FJ, Newton ILG, Cavanaugh CM. 2005. Chemosynthetic endosymbioses: adaptations to oxic-anoxic interfaces. Trends Microbiol 13:439_ 448.

5. König S, Gros O, Heiden SE, Hinzke T, Thürmer A, Poehlein A, Meyer S, Vatin Microbiol 2:16193.

6. Petersen JM, Kemper A, Gruber-Vodicka H, Cardini U, van der Geest M, Kleiner Weber M. 2016. Chemosynthetic symbionts of marine invertebrate animals are capable of nitrogen fixation. Nat Microbiol 2:16195.

7. Ponsard J, Cambon-Bonavita M-A, Zbinden M, Lepoint G, Joassin A, Corbari L, Shillito B, Durand L, Cueff-Gauchard V, Compère P. 2013. Inorganic carbon fixation by chemosynthetic ectosymbionts and nutritional transfers to the hydrothermal vent host-shrimp Rimicaris exoculata. ISME J 7:96-109.

8. Canfield DE, Thamdrup B. 2009. Towards a consistent classification scheme for geochemical environments, or, why we wish the term 'suboxic' would go away. Geobiology 7:385-392. 
Girguis PR. 2011. Thermodynamics and kinetics of sulfide oxidation by oxygen: a look at inorganically controlled reactions and biologically mediated processes in the environment. Front Microbiol 2:62. the sulfide gradient: a novel strategy involving marine nematodes and chemoautotrophic ectosymbionts. Mar Ecol 12:261-279.

11.Schiemer F, Novak R, Ott J. 1990. Metabolic studies on thiobiotic free-living nematodes and their symbiotic microorganisms. Mar Biol 106:129-137.

12. Ott J, Novak R. 1989. Living at an interface: Meiofauna at the oxygen/sulfide boundary in marine sediments, p. 415-422. In Ryland, JS, Tyler, PA (eds.), Reproduction, Genetics and Distributions of Marine Organisms. Olsen \& Olsen, Fredensborg.

13. Hentschel U, Berger E, Bright M, Felbeck H, Ott J. 1999. Metabolism of nitrogen and sulfur in ectosymbiotic bacteria of marine nematodes (Nematoda, Stilbonematinae). Mar Ecol Prog Ser 183:149-158.

14. Wilmot DB, Vetter RD. 1992. Oxygen- and nitrogen-dependent sulfur metabolism in the thiotrophic clam Solemya reidi. Biol Bull 182:444-453. symbionts of the bivalve Lucinoma aequizonata. Mar Ecol Prog Ser 94:35-41.

16. Hentschel U, Felbeck H. 1993. Nitrate respiration in the hydrothermal vent tubeworm Riftia pachyptila. Nature 366:338-340.

17. Freytag JK, Girguis PR, Bergquist DC, Andras JP, Childress JJ, Fisher CR. 2001. A paradox resolved: Sulfide acquisition by roots of seep tubeworms sustains net chemoautotrophy. Proc Natl Acad Sci U S A 98:13408-13413. 
invertebrates from sulphide-rich habitats. Nature 302:58-61.

895

896
19. Seston SL, Beinart RA, Sarode N, Shockey AC, Ranjan P, Ganesh S, Girguis PR, Stewart FJ. 2016. Metatranscriptional response of chemoautotrophic Ifremeria nautilei endosymbionts to differing sulfur regimes. Front Microbiol 7:1074.

20. Polz MF, Distel DL, Zarda B, Amann R, Felbeck H, Ott JA, Cavanaugh CM. 1994. Phylogenetic analysis of a highly specific association between ectosymbiotic, sulfur-oxidizing bacteria and a marine nematode. Appl Environ Microbiol $60: 4461-4467$

21. Bayer C, Heindl NR, Rinke C, Lücker S, Ott J, Bulgheresi S. 2009. Molecular characterization of the symbionts associated with marine nematodes of the genus Robbea. Environ Microbiol Rep 1:136-144.

22. Williams KP, Gillespie JJ, Sobral BWS, Nordberg EK, Snyder EE, Shallom JM, Dickerman AW. 2010. Phylogeny of gammaproteobacteria. J Bacteriol 192:23052314.

23. Pende N, Leisch N, Gruber-Vodicka HR, Heindl NR, Ott J, den Blaauwen T, Bulgheresi S. 2014. Size-independent symmetric division in extraordinarily long cells. Nat Commun 5:4803.

24.Zimmermann J, Wentrup C, Sadowski M, Blazejak A, Gruber-Vodicka HR, Kleiner M, Ott JA, Cronholm B, De Wit P, Erséus C, Dubilier N. 2016. Closely coupled evolutionary history of ecto- and endosymbionts from two distantly related animal phyla. Mol Ecol 25:3203-3223.

25. Leisch N, Verheul J, Heindl NR, Gruber-Vodicka HR, Pende N, den Blaauwen T, Bulgheresi S. 2012. Growth in width and FtsZ ring longitudinal positioning in a gammaproteobacterial symbiont. Curr Biol 22:R831-R832.

26. Leisch N, Pende N, Weber PM, Gruber-Vodicka HR, Verheul J, Vischer NOE, 

by non-ring FtsZ in the gammaproteobacterial symbiont of Robbea hypermnestra. Nat Microbiol 2:1-5.

27.Pende N, Wang J, Weber PM, Verheul J, Kuru E, Rittmann SK-MR, Leisch N, VanNieuwenhze MS, Brun Y V, den Blaauwen T, Bulgheresi S. 2018. Hostpolarized cell growth in animal symbionts. Curr Biol 28:1039-1051.e5.

28. Powell EN, Crenshaw MA, Rieger RM. 1979. Adaptations to sulfide in the meiofauna of the sulfide system. I. 35S-sulfide accumulation and the presence of a sulfide detoxification system. J Exp Mar Bio Ecol 37:57-76.

29. Polz MF, Felbeck H, Novak R, Nebelsick M, Ott JA. 1992. Chemoautotrophic, sulfur-oxidizing symbiotic bacteria on marine nematodes: morphological and biochemical characterization. Microb Ecol 24:313-329.

30. Himmel D, Maurin LC, Gros O, Mansot J-L. 2009. Raman microspectrometry sulfur detection and characterization in the marine ectosymbiotic nematode Eubostrichus dianae (Desmodoridae, Stilbonematidae). Biol Cell 101:43-54.

31. Ott JA, Bauer-Nebelsick M, Novotny V. 1995. The genus Laxus Cobb, 1894 (Stilbonematinae, Nematoda) - description of two new species with ectosymbiotic chemoautotrophic bacteria. Proc Biol Soc Washingt 108:508-527. R, Li W, Gilna P, Joint I, Frias-Lopez J, Shi Y, Tyson G, Coleman M, Schuster S, Chisholm S, Delong E, Poretsky R, Hewson I, Sun S, Allen A, Zehr J, Moran M, Hewson I, Poretsky R, Beinart R, White A, Shi T, Bench S, Moisander P, Paerl R, Tripp H, Montoya J, Moran M, Zehr J, Hewson I, Poretsky R, Dyhrman S, Zielinski B, White A, Tripp H, Montoya J, Zehr J, Gifford S, Sharma S, Rinta-Kanto J, 

Hugenholtz P, Mettel C, Kim Y, Shrestha P, Liesack W, Giannoukos G, Ciulla D, 
Weiman M, Medigue C, Anders S, Huber W, Asmann Y, Klee E, Thompson E, interpretation of metatranscriptomic data. BMC Genomics 15:912.

33. Li H, Durbin R. 2009. Fast and accurate short read alignment with BurrowsWheeler transform. Bioinformatics 25:1754-1760.

34. Bankevich A, Nurk S, Antipov D, Gurevich AA, Dvorkin M, Kulikov AS, Lesin VM, Nikolenko SI, Pham S, Prjibelski AD, Pyshkin A V., Sirotkin A V., Vyahhi N, Tesler G, Alekseyev MA, Pevzner PA. 2012. SPAdes: a new genome assembly algorithm and its applications to single-cell sequencing. J Comput Biol 19:455477.

35. Parks DH, Imelfort M, Skennerton CT, Hugenholtz P, Tyson GW. 2015. CheckM: assessing the quality of microbial genomes recovered from isolates, single cells, and metagenomes. Genome Res 25:1043-1055.

36. Vallenet D, Calteau A, Dubois M, Amours P, Bazin A, Beuvin M, Burlot L, Bussell X, Fouteau S, Gautreau G, Lajus A, Langlois J, Planel R, Roche D, Rollin J, Rouy Z, Sabatet V, Médigue C. 2019. MicroScope: an integrated platform for the annotation and exploration of microbial gene functions through genomic, pangenomic and metabolic comparative analysis. Nucleic Acids Res 48:D579D589.

37. Kanehisa M, Sato Y, Kawashima M, Furumichi M, Tanabe M. 2016. KEGG as a reference resource for gene and protein annotation. Nucleic Acids Res 44:D457D462. 
and data mining with the Blast2GO suite. Nucleic Acids Res 36:3420-3435.

995

996

39. Bateman A. 2002. The Pfam protein families database. Nucleic Acids Res $30: 276-280$.

40. Finn RD, Clements J, Eddy SR. 2011. HMMER web server: interactive sequence similarity searching. Nucleic Acids Res 39:W29-W37.

41. Andrews S. 2010. FastQC: a quality control tool for high throughput sequence data.

42. Schmieder R, Edwards R. 2011. Quality control and preprocessing of metagenomic datasets. Bioinformatics 27:863-864.

43. Bolger AM, Lohse M, Usadel B. 2014. Trimmomatic: a flexible trimmer for Illumina sequence data. Bioinformatics 30:2114-2120.

44. König L, Siegl A, Penz T, Haider S, Wentrup C, Polzin J, Mann E, Schmitz-Esser S, Domman D, Horn M. 2017. Biphasic Metabolism and Host Interaction of a Chlamydial Symbiont. mSystems 2:e00202-16.

45. Li H, Handsaker B, Wysoker A, Fennell T, Ruan J, Homer N, Marth G, Abecasis G, Durbin R. 2009. The sequence alignment/map format and SAMtools. Bioinformatics 25:2078-2079.

46. Anders S, Pyl PT, Huber W. 2014. HTSeq - A Python framework to work with high-throughput sequencing data. Bioinformatics 31:166-169.

47. Gentleman RC, Carey VJ, Bates DM, Bolstad B, Dettling M, Dudoit S, Ellis B, Gautier L, Ge Y, Gentry J, Hornik K, Hothorn T, Huber W, lacus S, Irizarry R, Leisch F, Li C, Maechler M, Rossini AJ, Sawitzki G, Smith C, Smyth G, Tierney L, Yang JYH, Zhang J. 2004. Bioconductor: open software development for computational biology and bioinformatics. Genome Biol 5:R80.

48. Robinson MD, McCarthy DJ, Smyth GK. 2010. edgeR: a Bioconductor package 
for differential expression analysis of digital gene expression data. Bioinformatics 26:139-140.

49. R Core Team. 2017. R: a language and environment for statistical computing. Vienna, Austria.

50. Robinson MD, Oshlack A. 2010. A scaling normalization method for differential expression analysis of RNA-seq data. Genome Biol 11:R25.

51. Rapaport F, Khanin R, Liang Y, Pirun M, Krek A, Zumbo P, Mason CE, Socci ND, Betel D. 2013. Comprehensive evaluation of differential gene expression analysis methods for RNA-seq data. Genome Biol 14:R95.

52. Trump BF, Ericsson JL. 1965. The effect of the fixative solution on the ultrastructure of cells and tissues. A comparative analysis with particular attention to the proximal convoluted tubule of the rat kidney. Lab Investig 14:1245-1323.

53. Samek O, Obruča S, Šiler M, Sedláček $P$, Benešová $P$, Kučera D, Márova I, Ježek J, Bernatová S, Zemánek P. 2016. Quantitative Raman spectroscopy analysis of polyhydroxyalkanoates produced by Cupriavidus necator $\mathrm{H} 16$. Sensors 16:1808.

54. Koppelman C-M, Aarsman MEG, Postmus J, Pas E, Muijsers AO, Scheffers D-J, Nanninga N, Den Blaauwen T. 2004. R174 of Escherichia coli FtsZ is involved in membrane interaction and protofilament bundling, and is essential for cell division. Mol Microbiol 51:645-657.

55. Schneider CA, Rasband WS, Eliceiri KW. 2012. NIH Image to ImageJ: 25 years of image analysis. Nat Methods 9:671-675.

56. Dahl C. 2017. Sulfur Metabolism in Phototrophic Bacteria, p. 27-66. In Modern Topics in the Phototrophic Prokaryotes. Springer International Publishing, Cham. 57. Ghosh W, Dam B. 2009. Biochemistry and molecular biology of lithotrophic sulfur 
oxidation by taxonomically and ecologically diverse bacteria and archaea. FEMS Microbiol Rev 33:999-1043.

58. Chen J, Strous M. 2013. Denitrification and aerobic respiration, hybrid electron transport chains and co-evolution. Biochim Biophys Acta - Bioenerg 1827:136144.

59. Wells M, Kanmanii NJ, AI Zadjali AM, Janecka JE, Basu P, Oremland RS, Stolz JF. 2020. Methane, arsenic, selenium and the origins of the DMSO reductase family. Sci Rep 10:1-14.

60. Lonjers ZT, Dickson EL, Chu T-PT, Kreutz JE, Neacsu FA, Anders KR, Shepherd JN. 2012. Identification of a new gene required for the biosynthesis of rhodoquinone in Rhodospirillum rubrum. J Bacteriol 194:965-971.

61. Stairs CW, Eme L, Muñoz-Gómez SA, Cohen A, Dellaire G, Shepherd JN, Fawcett JP, Roger AJ. 2018. Microbial eukaryotes have adapted to hypoxia by horizontal acquisitions of a gene involved in rhodoquinone biosynthesis. Elife 7:e34292.

62. Mills JK, Needham

D. 2005. Lysolipid incorporation

in dipalmitoylphosphatidylcholine bilayer membranes enhances the ion permeability and drug release rates at the membrane phase transition. Biochim Biophys Acta - Biomembr 1716:77-96.

63. Arouri A, Mouritsen OG. 2013. Membrane-perturbing effect of fatty acids and lysolipids. Prog Lipid Res 52:130-140.

64. Koshy C, Schweikhard ES, Gärtner RM, Perez C, Yildiz Ö, Ziegler C. 2013. Structural evidence for functional lipid interactions in the betaine transporter BetP. EMBO J 32:3096-3105.

65. Laganowsky A, Reading E, Allison TM, Ulmschneider MB, Degiacomi MT, 
Baldwin AJ, Robinson C V. 2014. Membrane proteins bind lipids selectively to modulate their structure and function. Nature 510:172-175. I, Splinter-Bondurant S, Brown B, Manzella L, Snir E, Almabrazi H, Scheetz TE, Bonaldo M de F, Casavant TL, Soares MB, Cronan JE, Reed JL, Ruby EG, McFall-Ngai MJ. 2010. Transcriptional patterns in both host and bacterium underlie a daily rhythm of anatomical and metabolic change in a beneficial symbiosis. Proc Natl Acad Sci U S A 107:2259-2264.

67. Saito HE, Harp JR, Fozo EM. 2014. Incorporation of exogenous fatty acids protects Enterococcus faecalis from membrane-damaging agents. Appl Environ Microbiol 80:6527-6538.

68. Nelson DC, Hagen KD, Edwards DB. 1995. The gill symbiont of the hydrothermal vent mussel Bathymodiolus thermophilus is a psychrophilic, chemoautotrophic, sulfur bacterium. Mar Biol 121:487-495.

69. Markert S, Arndt C, Felbeck H, Becher D, Sievert SM, Hügler M, Albrecht D, Robidart J, Bench S, Feldman RA, Hecker M, Schweder T. 2007. Physiological proteomics of the uncultured endosymbiont of Riftia pachyptila. Science 315:247250.

70. Volland J-M, Schintlmeister A, Zambalos H, Reipert S, Mozetič P, EspadaHinojosa S, Turk V, Wagner M, Bright M. 2018. NanoSIMS and tissue autoradiography reveal symbiont carbon fixation and organic carbon transfer to giant ciliate host. ISME J 12:714-727.

71. Seah BKB, Antony CP, Huettel B, Zarzycki J, Schada von Borzyskowski L, Erb TJ, Kouris A, Kleiner M, Liebeke M, Dubilier N, Gruber-Vodicka HR. 2019. Oxidizing symbionts without canonical genes for autotrophic $\mathrm{CO} 2$ fixation. MBio 
10:e01112-19.

72. Tsai YCC, Lapina MC, Bhushan S, Mueller-Cajar O. 2015. Identification and characterization of multiple rubisco activases in chemoautotrophic bacteria. Nat Commun 6:8883.

73. Kleiner M, Wentrup C, Lott C, Teeling H, Wetzel S, Young J, Chang Y-J, Shah M, VerBerkmoes NC, Zarzycki J, Fuchs G, Markert S, Hempel K, Voigt B, Becher D, Liebeke M, Lalk M, Albrecht D, Hecker M, Schweder T, Dubilier N. 2012. Metaproteomics of a gutless marine worm and its symbiotic microbial community reveal unusual pathways for carbon and energy use. Proc Natl Acad Sci U S A 109:E1173-E1182.

74. Jäckle O, Seah BKB, Tietjen M, Leisch N, Liebeke M, Kleiner M, Berg JS, GruberVodicka HR. 2019. Chemosynthetic symbiont with a drastically reduced genome serves as primary energy storage in the marine flatworm Paracatenula. Proc Natl Acad Sci U S A 116:8505-8514.

75. Chai Y, Kolter R, Losick R. 2009. A widely conserved gene cluster required for lactate utilization in Bacillus subtilis and its involvement in biofilm formation. $J$ Bacteriol 191:2423-2430.

76. Horswill AR, Escalante-Semerena JC. 1999. The prpE gene of Salmonella typhimurium LT2 encodes propionyl-CoA synthetase. Microbiology 145:13811388.

77. Mulligan C, Fischer M, Thomas GH. 2011. Tripartite ATP-independent periplasmic (TRAP) transporters in bacteria and archaea. FEMS Microbiol Rev 35:68-86.

78. Rogers A, Gibon Y, Stitt M, Morgan PB, Bernacchi CJ, Ort DR, Long SP. 2006. Increased $\mathrm{C}$ availability at elevated carbon dioxide concentration improves $\mathrm{N}$ 
assimilation in a legume. Plant, Cell Environ 29:1651-1658.

79. Elgharably A, Marschner P. 2011. Microbial activity and biomass and $\mathrm{N}$ and $\mathrm{P}$ availability in a saline sandy loam amended with inorganic $\mathrm{N}$ and lupin residues. Eur J Soil Biol 47:310-315.

80. Fellbaum CR, Gachomo EW, Beesetty Y, Choudhari S, Strahan GD, Pfeffer PE, Kiers ET, Bucking H. 2012. Carbon availability triggers fungal nitrogen uptake and transport in arbuscular mycorrhizal symbiosis. Proc Natl Acad Sci 109:26662671.

81. Hill S. 1988. How is nitrogenase regulated by oxygen? FEMS Microbiol Lett $54: 111-129$.

82. Burgess BK, Lowe DJ. 1996. Mechanism of molybdenum nitrogenase. Chem Rev 96:2983-3012.

83. Schneider S, SchintImeister A, Becana M, Wagner M, Woebken D, Wienkoop S. 2019. Sulfate is transported at significant rates through the symbiosome membrane and is crucial for nitrogenase biosynthesis. Plant Cell Environ 42:1180-1189.

84. Yeo W-S, Lee J-H, Lee K-C, Roe J-H. 2006. IscR acts as an activator in response to oxidative stress for the suf operon encoding Fe-S assembly proteins. Mol Microbiol 61:206-218.

85.Zeller T, Moskvin O V., Li K, Klug G, Gomelsky M. 2005. Transcriptome and physiological responses to hydrogen peroxide of the facultatively phototrophic bacterium Rhodobacter sphaeroides. J Bacteriol 187:7232-7242.

86. Grant CM. 2001. Role of the glutathione/glutaredoxin and thioredoxin systems in yeast growth and response to stress conditions. Mol Microbiol 39:533-541.

87. Alba BM, Leeds JA, Onufryk C, Lu CZ, Gross CA. 2002. DegS and YaeL 
participate sequentially in the cleavage of RseA to activate the sigma $\mathrm{E}$ dependent extracytoplasmic stress response. Genes Dev 16:2156-2168.

88. Sakoh M, Ito K, Akiyama Y. 2005. Proteolytic activity of HtpX, a membrane-bound and stress-controlled protease from Escherichia coli. J Biol Chem 280:3330533310.

89. Puri N, Karzai AW. 2017. HspQ functions as a unique specificity-enhancing factor for the AAA+ Lon protease. Mol Cell 66:672-683.e4. AB, Yura T, Yamanaka K, Niki H, Hiraga S, Ogura T. 1995. Escherichia coli FtsH is a membrane-bound, ATP-dependent protease which degrades the heat-shock transcription factor $\sigma 32$. EMBO J 14:2551-2560.

91. Schoemaker JM, Gayda RC, Markovitz A. 1984. Regulation of cell division in Escherichia coli: SOS induction and cellular location of the SulA protein, a key to Ion-associated filamentation and death. J Bacteriol 158:551-561.

92. Sargentini NJ, Smith KC. 1986. Quantitation of the involvement of the recA, recB, recC, recF, recJ, recN, lexA, radA, radB, uvrD, and umuC genes in the repair of X-ray-induced DNA double-strand breaks in Escherichia coli. Radiat Res 107:5872.

93. Au KG, Cabrera M, Miller JH, Modrich P. 1988. Escherichia coli mutY gene product is required for specific A-G----C.G mismatch correction. Proc Natl Acad Sci 85:9163-9166.

94. Deaconescu AM, Darst SA. 2005. Crystallization and preliminary structure determination of Escherichia coli Mfd, the transcription-repair coupling factor. Acta Crystallogr Sect F Struct Biol Cryst Commun 61:1062-1064.

95. Traxler MF, Summers SM, Nguyen H-T, Zacharia VM, Hightower GA, Smith JT, 
Conway T. 2008. The global, ppGpp-mediated stringent response to amino acid starvation in Escherichia coli. Mol Microbiol 68:1128-1148.

96. Magnusson LU, Farewell A, Nyström T. 2005. ppGpp: A global regulator in Escherichia coli. Trends Microbiol 13:236-242.

97. Rao SG, Ponnalagu D, Sukur S, Singh H, Sanghvi S, Mei Y, Jin DJ, Singh H. 2017. Identification and characterization of a bacterial homolog of chloride intracellular channel (CLIC) protein. Sci Rep 7:1-13.

98. Williams MD, Ouyang TX, Flickinger MC. 1994. Starvation-induced expression of SspA and SspB: the effects of a null mutation in sspA on Escherichia coli protein synthesis and survival during growth and prolonged starvation. Mol Microbiol 11:1029-1043.

99. Hansen A-M, Lehnherr H, Wang X, Mobley V, Jin DJ. 2003. Escherichia coli SspA is a transcription activator for bacteriophage $\mathrm{P} 1$ late genes. Mol Microbiol 48:1621-1631.

100. Chen J, Shen J, Solem C, Jensen PR. 2013. Oxidative stress at high temperatures in Lactococcus lactis due to an insufficient supply of riboflavin. Appl Environ Microbiol 79:6140-6147.

101. Ferrer A, Rivera J, Zapata C, Norambuena J, Sandoval Á, Chávez R, Orellana O, Levicán G. 2016. Cobalamin protection against oxidative stress in the

102. Showman AC, Aranjuez G, Adams PP, Jewett MW. 2016. Gene bb0318 is acidophilic iron-oxidizing bacterium Leptospirillum group II CF-1. Front Microbiol $7: 748$.

103. Typas A, Banzhaf M, Gross CA, Vollmer W. 2012. From the regulation of 
peptidoglycan synthesis to bacterial growth and morphology. Nat Rev Microbiol 10:123-136.

104. Meyers M, Fossing H, Powell E. 1987. Microdistribution of interstitial meiofauna, oxygen and sulfide gradients, and the tubes of macro-infauna. Mar Ecol Prog Ser 35:223-241.

105. Powell E. 1989. Oxygen, sulfide and diffusion: Why thiobiotic meiofauna must be sulfide-insensitive first-order respirers. J Mar Res 47:887-932.

106. Jan C, Petersen JM, Werner J, Teeling H, Huang S, Glöckner FO, Golyshina O V., Dubilier N, Golyshin PN, Jebbar M, Cambon-Bonavita M-A. 2014. The gill chamber epibiosis of deep-sea shrimp Rimicaris exoculata: an in-depth metagenomic investigation and discovery of Zetaproteobacteria. Environ Microbiol 16:2723-2738.

107. Ponnudurai R, Sayavedra L, Kleiner M, Heiden SE, Thürmer A, Felbeck H, Stand Genomic Sci 12:50.

108. Ponnudurai R, Kleiner M, Sayavedra L, Petersen JM, Moche M, Otto A, Becher and physiological interdependencies in the Bathymodiolus azoricus symbiosis. ISME J 11:463-477.

109. Fenchel T. 1970. Studies on the decomposition of organic detritus derived from the turtle grass Thalassia testudinum. Limnol Oceanogr 15:14-20.

110. Fenchel TM, Riedl RJ. 1970. The sulfide system: a new biotic community underneath the oxidized layer of marine sand bottoms. Mar Biol 7:255-268. 
112. Dahl C, Friedrich C, Kletzin A. 2008. Sulfur Oxidation in ProkaryotesEncyclopedia of Life Sciences. John Wiley \& Sons, Ltd, Chichester, UK.

113. Weber PM, Moessel F, Paredes GF, Viehboeck T, Vischer NOE, Bulgheresi S. 2019. A bidimensional segregation mode maintains symbiont chromosome orientation toward its host. Curr Biol 29:3018-3028.e4.

114. Schwedt A, Kreutzmann AC, Polerecky L, Schulz-Vogt HN. 2012. Sulfur respiration in a marine chemolithoautotrophic Beggiatoa strain. Front Microbiol 2:276.

115. Nyström T, Neidhardt FC. 1992. Cloning, mapping and nucleotide sequencing of a gene encoding a universal stress protein in Eschericha coli. Mol Microbiol 6:3187-3198.

116. Aldsworth TG, Sharman RL, Dodd CER. 1999. Bacterial suicide through stress. Cell Mol Life Sci 56:378-383.

117. Nyström T. 2001. Not quite dead enough: on bacterial life, culturability, senescence, and death. Arch Microbiol 176:159-164.

118. Nyström T. 2002. Translational fidelity, protein oxidation, and senescence: lessons from bacteria. Ageing Res Rev 1:693-703.

119. Sat B, Reches M, Engelberg-Kulka H. 2003. The Escherichia coli mazEF suicide module mediates thymineless death. J Bacteriol 185:1803-1807.

120. Weber H, Engelmann S, Becher D, Hecker M. 2004. Oxidative stress triggers thiol oxidation in the glyceraldehyde-3- phosphate dehydrogenase of Staphylococcus aureus. Mol Microbiol 52:133-140.

121. Page R, Peti W. 2016. Toxin-antitoxin systems in bacterial growth arrest and persistence. Nat Chem Biol 12:208-214. 
122. Hoor AT ten. 1981. Cell yield and bioenergetics of Thiomicrospira denitrificans compared with Thiobacillus denitrificans. Antonie Van Leeuwenhoek 47:231243.

123. Sorokin DY, Tourova TP, Antipov AN, Muyzer G, Kuenen JG. 2004. Anaerobic growth of the haloalkaliphilic denitrifying sulfur-oxidizing bacterium Thialkalivibrio thiocyanodenitrificans sp. nov. with thiocyanate. Microbiology 150:2435-2442.

124. Nunoura T, Takaki Y, Kazama H, Kakuta J, Shimamura S, Makita H, Hirai M, Miyazaki M, Takai K. 2014. Physiological and genomic features of a novel sulfuroxidizing gammaproteobacterium belonging to a previously uncultivated symbiotic lineage isolated from a hydrothermal vent. PLoS One 9:e104959.

125. Justin P, Kelly DP. 1978. Growth kinetics of Thiobacillus denitrificans in anaerobic and aerobic chemostat culture. J Gen Microbiol 107:123-130.

126. Childress JJ, Fisher CR, Favuzzi JA, Sanders NK. 1991. Sulfide and carbon dioxide uptake by the hydrothermal vent clam, Calyptogena magnifica, and its chemoautotrophic symbionts. Physiol Zool 64:1444-1470.

127. Scott KM, Cavanaugh CM. 2007. CO2 uptake and fixation by endosymbiotic chemoautotrophs from the bivalve Solemya velum. Appl Environ Microbiol 73:1174-1179.

128. Jordan DB, Ogren WL. 1981. Species variation in the specificity of ribulose biphosphate carboxylase/oxygenase. Nature 291:513-515.

129. Badger MR, Bek E jane. 2008. Multiple Rubisco forms in proteobacteria: their functional significance in relation to $\mathrm{CO} 2$ acquisition by the CBB cycle. J Exp Bot 59:1525-1541.

130. Tabita FR, Satagopan S, Hanson TE, Kreel NE, Scott SS. 2007. Distinct form I, II, III, and IV Rubisco proteins from the three kingdoms of life provide clues 
about Rubisco evolution and structure/function relationships. J Exp Bot $59: 1515-1524$.

131. Erb TJ. 2011. Carboxylases in natural and synthetic microbial pathways. Appl Environ Microbiol 77:8466-8477.

132. Wilmot DB, Vetter RD. 1990. The bacterial symbiont from the hydrothermal vent tubeworm Riftia pachyptila is a sulfide specialist. Mar Biol 106:273-283.

133. Fisher CR, Childress JJ, Minnich E. 1989. Autotrophic carbon fixation by the chemoautotrophic symbionts of Riftia pachyptila. Biol Bull 177:372-385.

134. Woyke T, Teeling H, Ivanova NN, Huntemann M, Richter M, Gloeckner FO, Boffelli D, Anderson IJ, Barry KW, Shapiro HJ, Szeto E, Kyrpides NC, Mussmann M, Amann R, Bergin C, Ruehland C, Rubin EM, Dubilier N. 2006. Symbiosis insights through metagenomic analysis of a microbial consortium. Nature 443:950-955.

135. Hagen KD, Nelson DC. 1996. Organic carbon utilization by obligately and facultatively autotrophic Beggiatoa strains in homogeneous and gradient cultures. Appl Environ Microbiol 62:947-953.

136. Kurian D, Jansèn T, Mäenpää P. 2006. Proteomic analysis of heterotrophy in Synechocystis sp. PCC 6803. Proteomics 6:1483-1494.

137. Norris PR, Clark DA, Owen JP, Waterhouse S. 1996. Characteristics of Sulfobacillus acidophilus sp. nov. and other moderately thermophilic mineralsulphide-oxidizing bacteria. Microbiology 142:775-783.

138. Breznak JA, Blum JS. 1991. Mixotrophy in the termite gut acetogen, Sporomusa termitida. Arch Microbiol 156:105-110.

139. Wan N, Abernathy M, Tang JKH, Tang YJ, You L. 2015. Cyanobacterial photodriven mixotrophic metabolism and its advantages for biosynthesis. Front Chem 
Sci Eng 9:308-316.

140. Zarzycki J, Fuchs G. 2011. Coassimilation of organic substrates via the autotrophic 3-hydroxypropionate bi-cycle in Chloroflexus aurantiacus. Appl Environ Microbiol 77:6181-6188.

141. Shimizu R, Dempo Y, Nakayama Y, Nakamura S, Bamba T, Fukusaki E, Fukui T. 2015. New insight into the role of the calvin cycle: Reutilization of CO2 emitted through sugar degradation. Sci Rep 5:1-12.

142. Shimizu R, Chou K, Orita I, Suzuki Y, Nakamura S, Fukui T. 2013. Detection of phase-dependent transcriptomic changes and Rubisco-mediated $\mathrm{CO} 2$ fixation into poly (3-hydroxybutyrate) under heterotrophic condition in Ralstonia eutropha H16 based on RNA-seq and gene deletion analyses. BMC Microbiol 13:169.

143. Makowka A, Nichelmann L, Schulze D, Spengler K, Wittmann C, Forchhammer K, Gutekunst K. 2020. Glycolytic shunts replenish the Calvin-Benson-Bassham cycle as anaplerotic reactions in Cyanobacteria. Mol Plant 13:471-482.

144. Unrein F, Gasol JM, Not F, Forn I, Massana R. 2014. Mixotrophic haptophytes are key bacterial grazers in oligotrophic coastal waters. ISME J 8:164-176.

145. Anderson AJ, Dawes EA. 1990. Occurrence, metabolism, metabolic role, and industrial uses of bacterial polyhydroxyalkanoates. Microbiol Rev. American Society for Microbiology (ASM).

146. Escapa IF, García JL, Bühler B, Blank LM, Prieto MA. 2012. The polyhydroxyalkanoate metabolism controls carbon and energy spillage in Pseudomonas putida. Environ Microbiol 14:1049-1063.

147. Verlinden RAJ, Hill DJ, Kenward MA, Williams CD, Radecka I. 2007. Bacterial synthesis of biodegradable polyhydroxyalkanoates. J Appl Microbiol. John Wiley \& Sons, Ltd. 
148. Tal S, Okon Y. 1985. Production of the reserve material poly- $\beta$-hydroxybutyrate and its function in Azospirillum brasilense Cd. Can J Microbiol 31:608-613.

149. Natarajan K, Kishore L, Babu CR. 1995. Characteristics of $\mathrm{NaCl}$ stress associated proteins of Rhizobium under varying cultural conditions. J Basic Microbiol 35:413-420.

150. Steinbüchel A, Füchtenbusch B. 1998. Bacterial and other biological systems for polyester production. Trends Biotechnol 16:419-427.

151. Kadouri D, Burdman S, Jurkevitch E, Okon Y. 2002. Identification and isolation of genes involved in poly(beta-hydroxybutyrate) biosynthesis in Azospirillum brasilense and characterization of a phbC mutant. Appl Environ Microbiol 68:2943-2949.

152. Ayub ND, Pettinari MJ, Ruiz JA, López NI. 2004. A polyhydroxybutyrateproducing Pseudomonas sp. isolated from antarctic environments with high stress resistance. Curr Microbiol 49:170-174.

153. Kadouri D, Jurkevitch E, Okon Y, Castro-Sowinski S. 2005. Ecological and agricultural significance of bacterial polyhydroxyalkanoates. Crit Rev Microbiol $31: 55-67$.

154. Obruca S, Sedlacek P, Krzyzanek V, Mravec F, Hrubanova K, Samek O, Kucera D, Benesova P, Marova I. 2016. Accumulation of poly(3-hydroxybutyrate) helps bacterial cells to survive freezing. PLoS One 11:e0157778.

155. Obruca S, Sedlacek P, Mravec F, Krzyzanek V, Nebesarova J, Samek O, Kucera D, Benesova P, Hrubanova K, Milerova M, Marova I. 2017. The presence of PHB granules in cytoplasm protects non-halophilic bacterial cells against the harmful impact of hypertonic environments. N Biotechnol 39:68-80.

156. Slaninova E, Sedlacek P, Mravec F, Mullerova L, Samek O, Koller M, Hesko O, 
Kucera D, Marova I, Obruca S. 2018. Light scattering on PHA granules protects bacterial cells against the harmful effects of UV radiation. Appl Microbiol Biotechnol 102:1923-1931.

157. Hamad MA, Austin CR, Stewart AL, Higgins M, Vázquez-Torres A, Voskuil MI. 2011. Adaptation and antibiotic tolerance of anaerobic Burkholderia pseudomallei. Antimicrob Agents Chemother 55:3313-3323.

158. Kim JK, Won YJ, Nikoh N, Nakayama H, Han SH, Kikuchi Y, Rhee YH, Park HY, Kwon JY, Kurokawa K, Dohmae N, Fukatsu T, Lee BL. 2013. Polyester synthesis genes associated with stress resistance are involved in an insect-bacterium symbiosis. Proc Natl Acad Sci U S A 110:E2381-E2389.

159. Claessen D, Errington J. 2019. Cell wall deficiency as a coping strategy for stress. Trends Microbiol 27:1025-1033.

160. McKinlay JB, Harwood CS. 2010. Carbon dioxide fixation as a central redox cofactor recycling mechanism in bacteria. Proc Natl Acad Sci U S A 107:11669_ 11675.

161. Bentzon-Tilia M, Severin I, Hansen LH, Riemann L. 2015. Genomics and ecophysiology of heterotrophic nitrogen-fixing bacteria isolated from estuarine surface water. MBio 6:e00929-15.

162. Antia NJ, Harrison PJ, Oliveira L. 1991. The role of dissolved organic nitrogen in phytoplankton nutrition, cell biology and ecology. Phycologia 30:1-89.

163. Walsh P, Wang Y, Campbell C, Boeck DG, Wood C. 2001. Patterns of nitrogenous waste excretion and gill urea transporter mRNA expression in several species of marine fish. Mar Biol 139:839-844. the urea uptake system and transcriptional analysis of urea transporter- and 
urease-encoding genes in Corynebacterium glutamicum. J Bacteriol 186:76457652.

165. Brown DR, Barton G, Pan Z, Buck M, Wigneshweraraj S. 2014. Nitrogen stress response and stringent response are coupled in Escherichia coli. Nat Commun 5.

166. Ashoori M, Saedisomeolia A. 2014. Riboflavin (vitamin B2) and oxidative stress: a review. Br J Nutr 111:1985-1991.

167. Gould RL, Pazdro R. 2019. Impact of supplementary amino acids, micronutrients, and overall diet on glutathione homeostasis. Nutrients 11:1056.

168. Carmel-Harel O, Storz G. 2000. Roles of the glutathione- and thioredoxindependent reduction systems in the Escherichia coli and Saccharomyces cerevisiae responses to oxidative stress. Annu Rev Microbiol 54:439-461.

169. Williams $\mathrm{CH}$. 1995. Mechanism and structure of thioredoxin reductase from Escherichia coli. FASEB J 9:1267-1276.

170. Vanoni MA, Curti B. 1999. Glutamate synthase: a complex iron-sulfur flavoprotein. Cell Mol Life Sci 55:617-638.

171. Liang J, Han Q, Tan Y, Ding H, Li J. 2019. Current advances on structure-function relationships of pyridoxal 5'-phosphate-dependent enzymes. Front Mol Biosci 6:4. cobalamin-dependent enzymes. Annu Rev Biochem 72:209-247.

173. Fontecave M, Atta M, Mulliez E. 2004. S-adenosylmethionine: nothing goes to waste. Trends Biochem Sci 29:243-249.

174. Caro AA, Cederbaum Al. 2004. Antioxidant properties of S-adenosyl-I-methionine in Fe2+-initiated oxidations. Free Radic Biol Med 36:1303-1316. 
International Publishing, Cham.

Figure legends

Figure 1. Median gene expression levels of selected $\mathrm{Ca}$. T. oneisti metabolic processes under anoxic-sulfidic (AS) versus oxic (0) conditions. All genes involved in a particular process were manually collected and median expression levels ( $\log _{2}$ TPMs, transcripts per kilobase million) per condition and process are shown (horizontal bold lines). Importantly, metabolic processes include both differentially and constitutively expressed genes, and the total number of genes considered are indicated at the bottom of each process. For the specific assignment of genes see Data S1. Note that for the processes designated as 'Amino acids', 'Storage' and 'Vitamins \& cofactors' only the expression of the biosynthesis genes was considered. Boxes indicate interquartile ranges (25\%-75\%), whiskers refer to the minimum and maximum expression values, respectively. The individual processes are ordered according to the difference in median expression between AS and O conditions, i.e. sulfur oxidation (far left) had the largest difference in median expression between the two conditions, with higher median expression in the AS condition, whereas urea utilization (far right) had the largest difference in median expression, with higher median expression in the $O$ condition. Metabolic processes were considered highly expressed when their median expression level was above $5.2 \log _{2}$ TPM (dashed grey line), which represents the median expression of all expressed protein-coding genes ( $n=4747)$ under both 
median gene expression between conditions $\left({ }^{* *}, p<0.01 ;{ }^{* * *}, p<0.001\right)$. CBB cycle: Calvin-Benson-Bassham cycle.

\section{Figure 2. Oxidation of stored sulfur is coupled to denitrification but loosely} coupled to $\mathrm{CO}_{2}$ fixation under anoxic conditions. (A) Heatmap visualizing only differentially expressed genes (2-fold change, FDR $\leq 0.05$ ) involved in sulfur oxidation, denitrification and $\mathrm{CO}_{2}$ fixation via the Calvin-Benson-Bassham cycle between the anoxic-sulfidic (AS) and oxic (O) conditions after $24 \mathrm{~h}$ of incubation. Expression levels are visualized by displaying mean-centered $\log _{2}$ TPMs (transcripts per kilobase million). Upregulation is indicated in red, downregulation in blue. Genes are ordered by function in the respective metabolic pathways. FCC: flavocytochrome c, S: sulfur, Dsr: dissimilatory sulfite reductase, APS: adenylylsulfate, Qmo: quinone-interacting membrane-bound oxidoreductase, Hdr: heterodisulfide reductase, Nap: periplasmic nitrate reductase, Nir: cd1 nitrite reductase, qNor: quinol-dependent nitric oxide reductase, Nos: nitrous oxide reductase, Siroheme synt.: siroheme biosynthesis (heme d precursor), RuBisCo su.: ribulose-1,5-bisphosphate carboxylase/oxygenase small subunit, PPi-PFK: PPi-dependent phosphofructokinase, $\mathrm{H}^{+}-\mathrm{PPase}$ : proton-translocating pyrophosphatase. (B) Relative ${ }^{13} \mathrm{C}$ isotope content of symbiotic L. oneistus as determined by EA-IRMS after $24 \mathrm{~h}$ incubations with ${ }^{13} \mathrm{C}$-labeled bicarbonate under anoxic-sulfidic conditions (AS; red dots), or in the presence of oxygen ( $\mathrm{O}$; dark blue: hypoxic, light blue: oxic). Dots refer to the values determined in individual measurements (comprising 50 worms per measurement, for further details see Table S2). Horizontal lines indicate means, error bars correspond to standard deviations. The categories ${ }^{12} \mathrm{C}$ live and ${ }^{13} \mathrm{C}$-dead refer to the natural isotope abundance control and the dead control, respectively. Different lower-case letters indicate significant differences among 
conditions (one-way ANOVA, Tukey's post-hoc test, $p<0.05$ ). Importantly, the hypoxic and oxic incubations were not pooled for the EA-IRMS analysis.

Figure 3. Nitrogen fixation and urea utilization genes are upregulated under oxic conditions. The heatmap only shows genes that were differentially expressed (2-fold change, FDR $\leq 0.05$ ) between anoxic-sulfidic (AS) and oxygenated $(\mathrm{O})$ conditions after $24 \mathrm{~h}$ of incubation. Expression levels are displayed as mean-centered $\log _{2}$ TPMs (transcripts per kilobase million). Upregulation is indicated in red, downregulation in blue. Genes are ordered by function in the respective metabolic pathway. Cofactor synt.: Cofactor biosynthesis, Urease acc. proteins: urease accessory proteins.

Figure 4. Stress response and vitamin biosynthesis genes are upregulated, and fewer symbiont cells divide in the presence of oxygen. (A) Heatmaps displaying transcript levels of genes involved in stress response, as well as in the biosynthesis of vitamins and cofactors. Expression levels are visualized by displaying mean-centered $\log _{2}$ TPMs (transcripts per kilobase million). Upregulation is indicated in red, and downregulation in blue. Genes are ordered by function in the respective metabolic pathways. Heavy metal rest.: heavy metal resistance. (B) Bars show the mean percentage of dividing $\mathrm{Ca}$. T. oneisti cells upon $24 \mathrm{~h}$ incubations under anoxic-sulfidic (AS) and in the presence of oxygen (O). The latter condition includes cells incubated under hypoxic and oxic conditions. A total of 658,1009 , and 1923 cells were counted for the AS, hypoxic and oxic condition, respectively. Error bars indicate $95 \%$ confidence intervals (Fisher's exact test).

Figure 5. Schematic representation of $\mathrm{Ca}$. T. oneisti's metabolism in deep anoxic 
and upper oxygenated sand. Our study suggests that in anoxic-sulfidic sediment zones (left) the ectosymbiont performs enhanced anaerobic sulfur oxidation coupled to nitrate reduction to nitrogen gas (denitrification). Additional electron acceptors such as fumarate, polysulfide $\left(\mathrm{Sn}^{2-}\right)$ or thiosulfate $\left(\mathrm{S}_{2} \mathrm{O}_{3}{ }^{2-}\right)$ may also be reduced. The storage compound PHA may serve as a carbon source (in addition to $\mathrm{CO}_{2}$ ) and an additional electron donor. Host-derived phospholipids (P-lipids) may be incorporated into the ectosymbiont's membrane to increase permeability. In superficial, oxygenated zones (right), oxygen triggers a global stress response that may not only consume energy and dampen proliferation, but may also require vitamin biosynthesis thereby increasing the demand for nitrogen. Small organic carbon compounds (Corg) putatively excreted by the host and incorporated by the ectosymbiont may contribute to energy generation (and carbon) via aerobic respiration, by the conversion of acetyl CoA via the TCA cycle (not depicted in the figure). Together with autotrophic $\mathrm{CO}_{2}$ fixation, $\mathrm{Corg}_{\text {may }}$ increase carbon availability, which would enable Ca. T. oneisti to synthesize PHA. Heme and other essential nutrients may be directly or indirectly transferred to the nematode host. Only processes predicted to dominate in one condition over the other are depicted in this model, although they likely occur under both conditions.

\section{SUPPLEMENTAL MATERIAL}

\section{Supplemental Figures}

Figure S1. Natural versus experimental conditions. (A) The left panel shows Laxus oneistus total counts per $6 \mathrm{~cm}$ core subsection from all 8 sandbars (horizontal beige bars) and corresponding mean sulfide $\left(\Sigma \mathrm{H}_{2} \mathrm{~S}\right)$ concentrations ( $\mu \mathrm{M}$, grey line). The right 
panel shows mean nitrate and nitrate concentrations through depth in the same sandbars of Carrie Bow Cay, Belize. Error bars represent the standard error of the mean. Note that a few nitrate and nitrite data points are derived from only two or one sandbars (Table S1). (B) Experimental set up of incubations for RNA-Seq, EA-IRMS and Raman microspectroscopy. Batches of 50 L. oneistus were incubated under different oxygen concentrations: anoxic with sulfide $\left(0 \mu \mathrm{M} \mathrm{O}_{2}, \leq 25 \mu \mathrm{M}\right.$ sodium sulfide added), anoxic without sulfide $\left(0 \mu \mathrm{M} \mathrm{O}_{2}\right)$, hypoxic $\left(<60 \mu \mathrm{M} \mathrm{O}_{2}\right.$ after $\left.24 \mathrm{~h}\right)$, and oxic $\left(>100 \mu \mathrm{M} \mathrm{O}_{2}\right.$ after $24 \mathrm{~h}$ ). The box around the anoxic incubation vials indicates that these incubations were carried out in a polyethylene isolation chamber. Given the similarity of gene expression profiles between the hypoxic and oxic samples (see Figure S2), most of the follow-up analyses were conducted by treating the hypoxic and oxic samples as biological replicates $(\mathrm{O})$, and comparing the $\mathrm{O}$ condition to the anoxic-sulfidic (AS) condition. All incubations were performed in $0.2 \mu \mathrm{M}$-filtered seawater and in biological triplicates.

Figure S2. RNA sequencing statistics, sample similarity and differential gene expression. (A) RNA sequencing and mapping statistics. Sequencing reads were mapped to the symbiont genome assembly consisting of 401 contigs and 5169 proteincoding genes. The total number of reads refers to the number of reads after quality filtering and trimming, and the number of reads mapped to the genome (i.e. genes, intergenic regions and antisense regions) only includes uniquely mapped reads. (B) Similarity between samples based on Euclidean distances between expression values (log2TPMs), visualized by means of multidimensional scaling (MDS). A total of 4797 protein-coding genes $(92.8 \%)$ were detected to be expressed. Most of the follow-up analyses were conducted comparing the anoxic-sulfidic conditions (AS, red circle) to conditions in which oxygen was present $(\mathrm{O}$, blue circle). (C) Differential expression (DE) 
analysis between hypoxic and oxic samples revealed that the number of DE genes was low (2.9\% of all expressed genes), and thus hypoxic and oxic samples were treated as biological replicates. $20.7 \%$ of all expressed genes were differentially expressed between AS and O conditions. Genes were considered differentially expressed if their expression changed twofold with a false-discovery rate $(F D R) \leq 0.05$.

Figure S3. Schematic representation of central metabolic pathways present in the Ca. T. oneisti genome. All gene names are indicated in Data S1. Organic carbon compounds such as acetate, lactate, propionate and glycerol 3-phosphate (glycerol-3P) could be host-derived. The respiratory chain of oxygen respiration $\left(\mathrm{O}_{2}\right.$ resp., blue) consists of NADH dehydrogenase (nuo genes, complex I), succinate dehydrogenase (sdh genes, complex II), the cytochrome bc1 complex (pet genes, complex III) and an aa3-type cytochrome c oxidase (cta genes, complex IV). Note that $\mathrm{Ca}$. T. oneisti only encodes a single complex IV enzyme. Grey: enzymes, brown: transporters, orange: storage compounds.

Figure S4. Gene expression heatmaps for sulfur oxidation and denitrification including the anoxic condition without sulfide. (A) Centered expression values of all genes that were differentially expressed between at least two conditions, are shown, with genes in bold that were both differentially expressed between both AS versus $O$ and anoxic without sulfide versus $O$ (twofold change, FDR $\leq 0.05$ ). Genes are ordered by function in the respective metabolic pathways. Note that the expression of many of the genes follows a clear pattern depending on whether oxygen is present or not. (B) Relative elemental sulfur $\left(\mathrm{S}^{0}\right)$ content in ectosymbionts as determined by Raman microspectroscopy after $24 \mathrm{~h}$ incubations under anoxic-sulfidic (AS; red dots), anoxic 
without added sulfide ( $\mathrm{A}$, black dots) or in the presence of oxygen (O; dark blue: hypoxic, light blue: oxic). Each dot refers to the value obtained from measuring an individual ectosymbiont cell. 50 cells were measured per condition. Horizontal lines display medians, boxes show the interquartile ranges (25-75\%), whiskers indicate minimum and maximum values, and different lower-case letters indicate significant differences among conditions $(p<0.05$, Kruskal-Wallis test and Dunn post-hoc test for multiple pairwise comparisons; $p$ (AS vs $A)=3.5 \mathrm{E}-17, p($ AS vs hypoxic $)=0.011, p($ AS vs oxic $)=7.4 \mathrm{E}-$ $13, \mathrm{p}(\mathrm{A}$ vs hypoxic $)=3.2 \mathrm{E}-09, \mathrm{p}(\mathrm{A}$ vs oxic $)=0.188, \mathrm{p}$ (hypoxic vs oxic $)=3.6 \mathrm{e}-06)$. Relative intensities below 1 (grey dashed line), indicate that elemental sulfur could not be detected. Percentage of cells with sulfur detected: $92 \%$ (AS), $14 \%$ (A), $76 \%$ (hypoxic), and 22\% (oxic).

Figure S5. Expression of genes involved in energy conservation other than sulfur oxidation and denitrification. Only genes that were differentially expressed between AS and $\mathrm{O}$ are shown (twofold change, FDR $\leq 0.05$ ). Genes are ordered by function. Glycerol-3P-DH: glycerol-3-phosphate dehydrogenase, Fumarate red.: fumarate reductase, Polysulfide/thiosulfate red.: Polysulfide/thiosulfate reductase.

\section{Figure S6. Lipid composition of ectosymbionts after incubation of symbiotic} nematodes in anoxic and oxic conditions. (A) Major lipid classes and their abundance relative to all lipids detected. (B) Relative abundance of significantly changed glycerophospholipids. Lipid class, fatty acid chain length and saturation are depicted on the $x$-axis. Note that PG is composed of two fatty acids, while lyso-phospholipids (LPG, LPE and LPC) only contain one fatty acid. Bars show mean abundances relative to total lipids (\%) and their standard deviations derived from three analytical replicates. The 
number of asterisks refers to the significance level (Student's t-test; ${ }^{*} \mathrm{P}<0.05,{ }^{*} \mathrm{P}<$ $\left.0.01,{ }^{* \star *} \mathrm{P}<0.001\right)$. Note that $\mathrm{Ca}$. T. oneisti does not encode for any known phosphatidylcholine biosynthesis genes. PG: phosphatidylglycerol, LPG: lysophosphatidylglycerol, LPE: lyso-phosphatidylethanolamine, LPC: lysophosphatidylcholine. For details on methodology see Supplementary Materials \& Methods.

Figure S7. NanoSIMS analysis of ${ }^{13} \mathrm{C}$ isotope incorporation in L. oneistus and its ectosymbiont after incubation in ${ }^{13} \mathrm{C}$-labeled bicarbonate for $24 \mathrm{~h}$ under anoxic conditions without sulfide. The ${ }^{13} \mathrm{C}$ content is displayed as ${ }^{13} \mathrm{C} /\left({ }^{12} \mathrm{C}+{ }^{13} \mathrm{C}\right)$ isotope fraction, given in at\%. (A) NanoSIMS images showing cellular ultrastructure, as displayed by the ${ }^{12} \mathrm{C}^{14} \mathrm{~N}$ - secondary ion signal intensity (left), and isotope label distribution (right) in cross sections of $L$. oneistus after incubation of living worms in isotopically labeled $\left({ }^{13} \mathrm{C}\right.$-live, top row) and unlabeled $\left({ }^{12} \mathrm{C}\right.$-live, bottom row) bicarbonate. Incubation of $2 \%$ PFA-fixed worms under identical conditions in isotopically labeled bicarbonate $\left({ }^{13} \mathrm{C}\right.$-dead, central row) served as a control for exclusion of unspecific (nonmetabolic) label uptake. Scale bars: $5 \mu \mathrm{m}$. (B) Region of interest (ROI)-specific evaluation of the isotopic label content, revealing significant ${ }^{13} \mathrm{C}$ enrichment both in the ectosymbiont cells and, within particular regions, also in the host tissue. For details on methodology see Supplementary Materials \& Methods.

Figure S8. Phylogenetic tree of the large subunit protein of the ribulose-1,5bisphosphate carboxylase/oxygenase (RuBisCO). Unrooted phylogenetic tree illustrating the four forms of RuBisCO from diverse organisms, such as plants, free-living and symbiotic bacteria. The CbbL protein of $\mathrm{Ca}$. T. oneisti is highlighted in red. Type I 
1593

1594

1595

1596

1597

1598

1599

1600

1601

1602

1603

1604

1605

1606

1607

1608

1609

1610

1611

1612

1613

1614

1615

1616

1617

(IA, IB, IC, ID): CbbL, type II: CbbM, type III, type IV: RuBisCO-like. The analysis is based on a MAFFT alignment of full-length amino acid sequences (Table S5) and was estimated under the $\mathrm{LG}+\mathrm{I}+\mathrm{G} 4$ model using Maximum Likelihood phylogeny (IQ-TREE) with node support calculated by SH-aLRT. The scale bar represents $0.5 \%$ estimated sequence divergence. SH-aLRT values at the nodes are based on 10000 replicates. For details on methodology see Supplementary Materials \& Methods.

Figure S9. Differentially expressed genes involved in biosynthesis and utilization of storage compounds and detection of PHA via Raman spectroscopy. (A) Only differentially expressed genes involved in PHA and trehalose metabolism are shown (2fold change, FDR $\leq 0.05$ ). (B) Relative PHA content measurement of 50 ectosymbiont cells per condition after $24 \mathrm{~h}$ of incubation analyzed by Raman spectroscopy. Horizontal lines indicate medians, boxes show interquartile ranges (25-75\%), and whiskers denote minimum and maximum measurements. Each dot represents a single ectosymbiont cell. Cells incubated in the presence of oxygen are depicted in one column $(\mathrm{O})$ but using different colors to indicate the two different oxygenated conditions (light blue: oxic, dark blue: hypoxic). Measurements represented by red dots were obtained from anoxicsulfidic (AS) incubations. PHA was detected in all conditions, although more PHA was detected in cells incubated in hypoxic incubations $(p<0.05$, Kruskal Wallis test, pairwise comparisons; $p$ (AS vs hypoxic) $=0.022, p($ AS vs oxic $)=0.057, p($ hypoxic vs oxic $)=$ 0.054 .

\section{Supplemental Tables}

Table S1. Sediment core nematode counts and chemical measurements 
Table S2. RNA-Seq and EA-IRMS incubation measurements. Note that RNA-Seq and 2017, whereas samples 4-6 in March 2019.

Table S3. Functional enrichments of selected gene sets. Statistical enrichment of functional categories was tested for GO terms (GO), Pfam domains (PF), KEGG metabolic maps (map), COG category (COG) and COG general category (uppercase letter) using the Bioconductor software package GOseq (M. D. Young, M. J. Wakefield, G. K. Smyth, and A. Oshlack, Genome Biol 11(2): R14, 2010, https://doi.org/10.1186/gb2010-11-2-r14). Functional categories among sets of protein-coding genes were significantly enriched if the adjusted $P$ value (false discovery rate, FDR) was $\leq 0.1$. Only FDR values below that threshold are shown; non-significant FDR values are indicated (NS). AS: anoxic-sulfidic; O: hypoxic + oxic.

Table S4. Top expressed Ca. T. oneisti proteins. Symbiont proteins under each condition were ranked by relative abundance (\%cOrgNSAF), and the 30 proteins with functional annotation exhibiting the highest relative abundance per condition are shown. Proteins written in bold were only found in the top expressed proteins under the respective condition. Color gradients indicate relative abundance and are scaled between values 5.76 and 0.39 . Relative abundance of symbiont proteins under two different conditions was determined as described in Supplementary Materials \& Methods and is displayed as mean values of three individual replicates per condition. Data S1 specifies all proteins that were detected to be expressed (column "Proteome detection"). 
Table S5. List of all ribulose-1,5-bisphosphate carboxylase (RuBisCO) protein sequences used for constructing the phylogenetic tree in Figure S8.

\section{Supplemental Dataset}

1648 Data S1. Ca. T. oneisti genes, functional annotations and expression. 


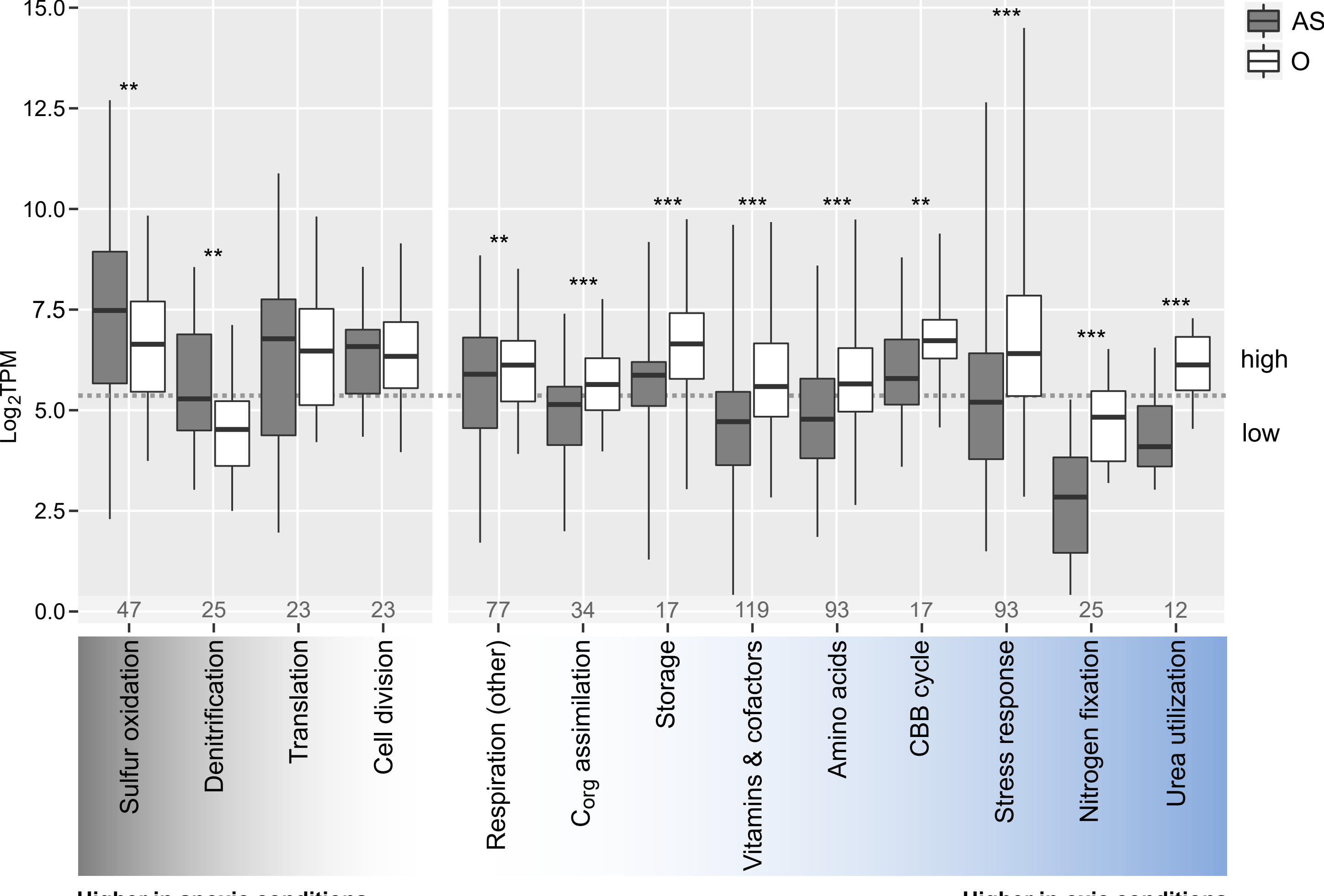


B

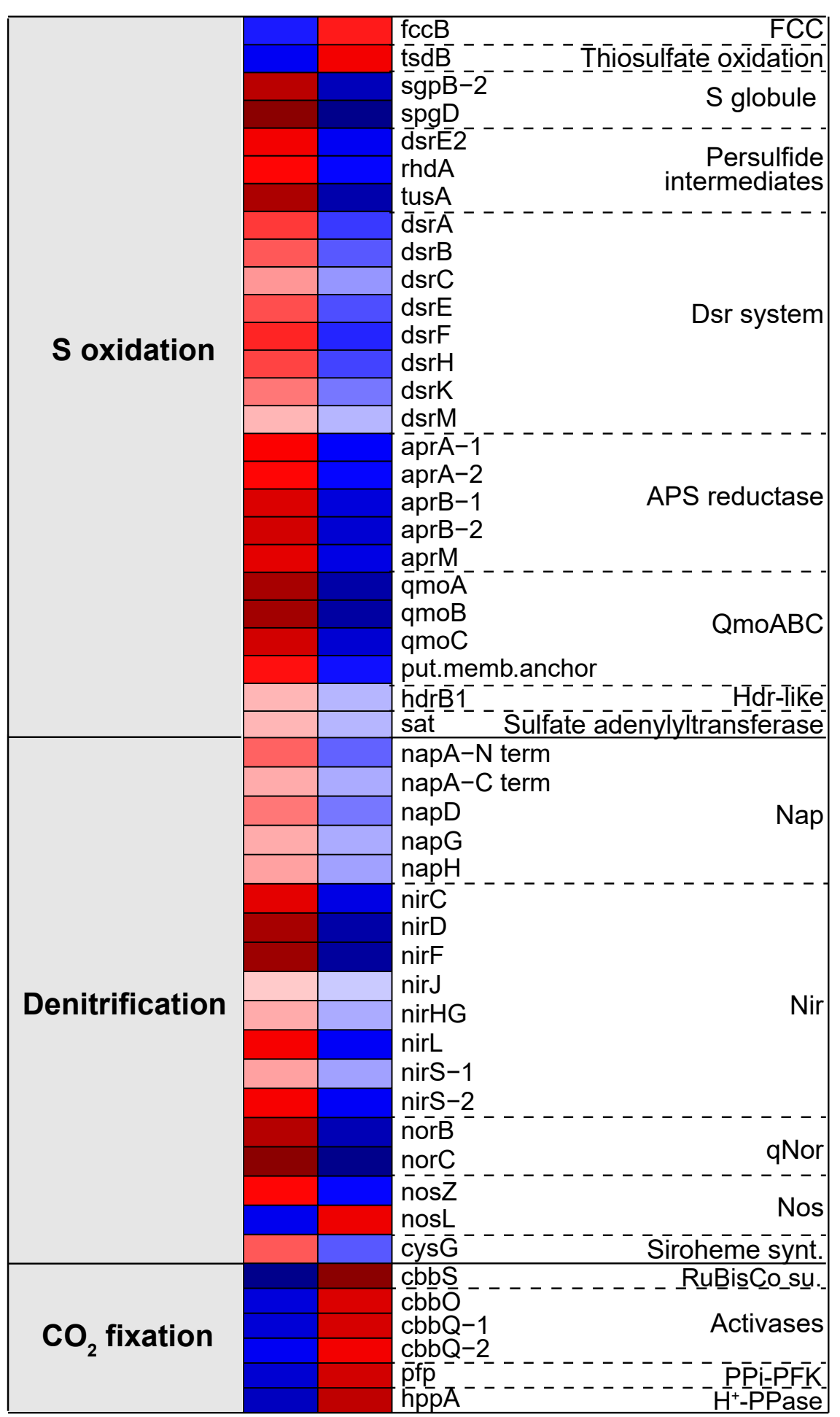

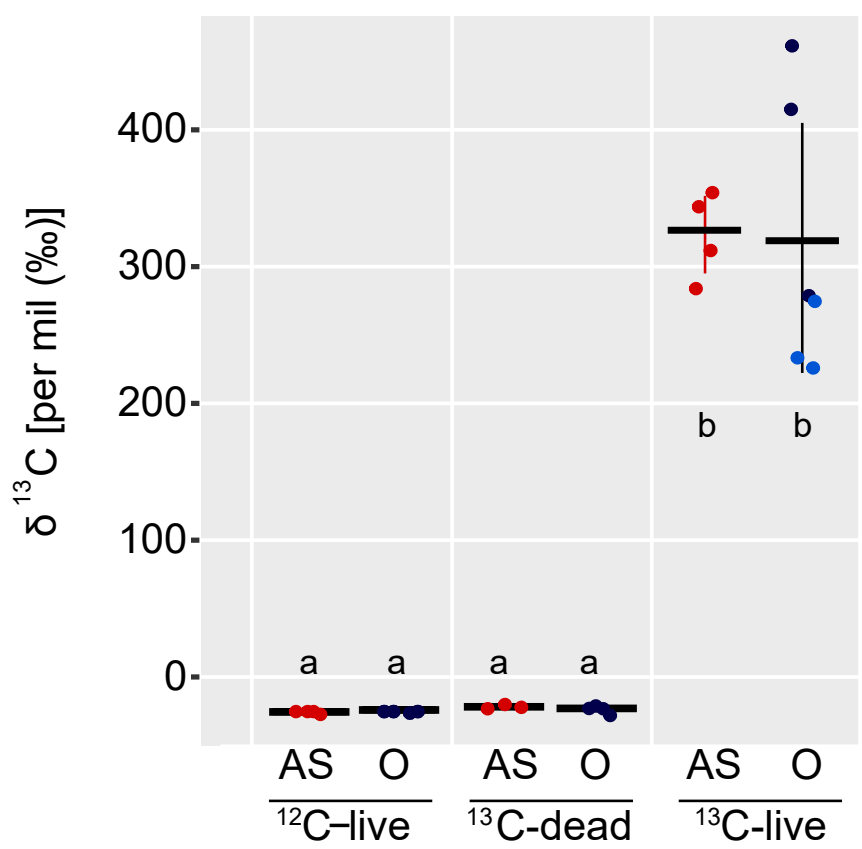




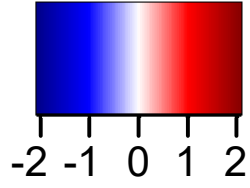
Centered $\log _{2}$ TPM

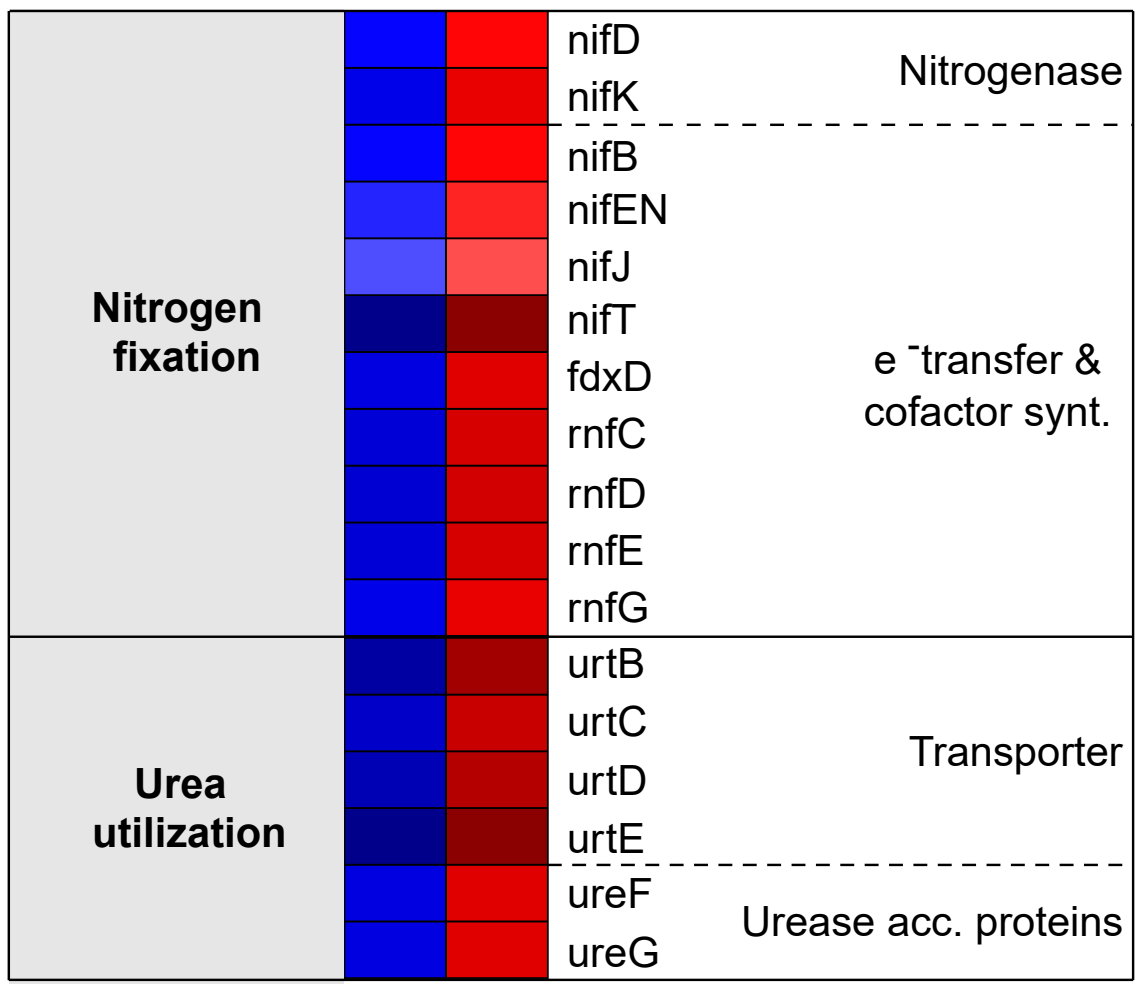


Cofactor \& vitamin biosynthesis

AS 0

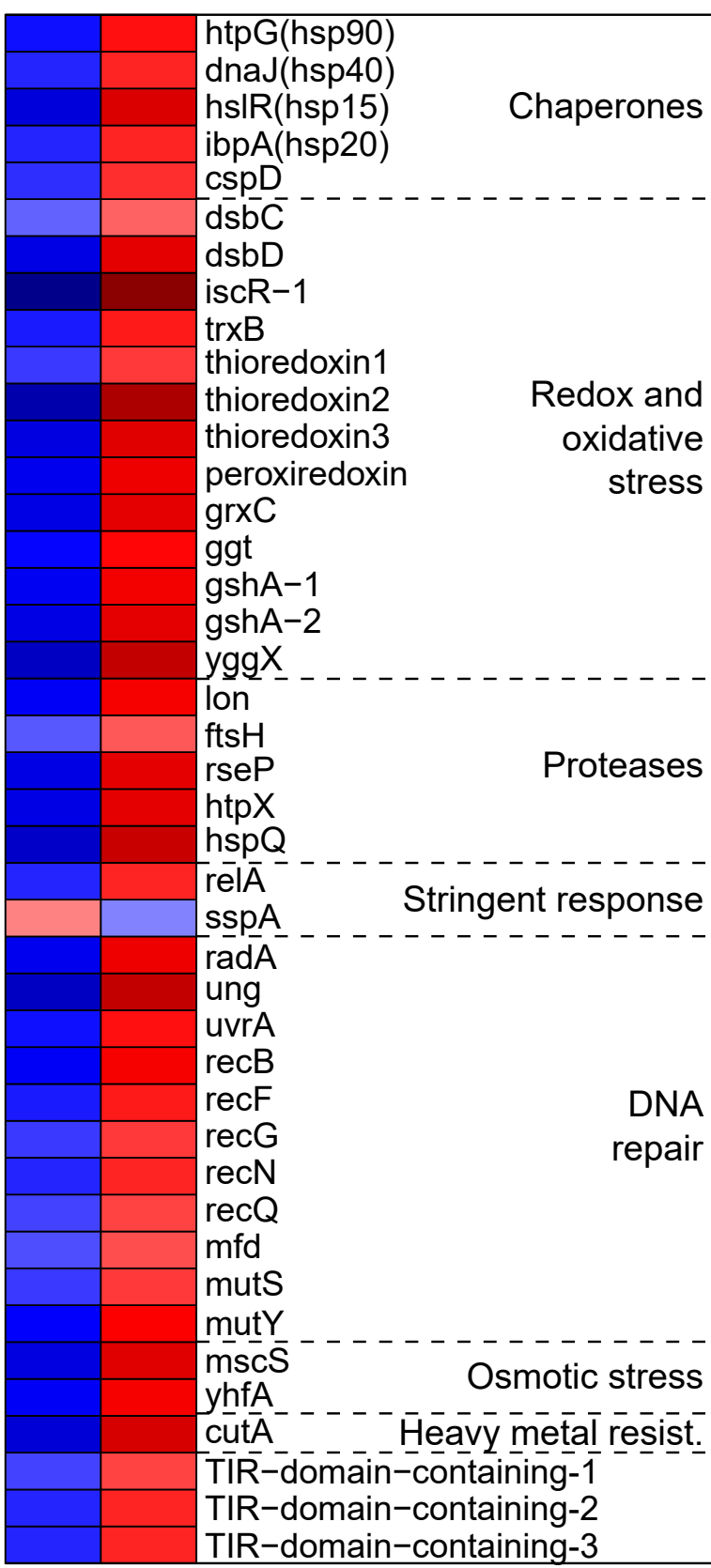

AS 0

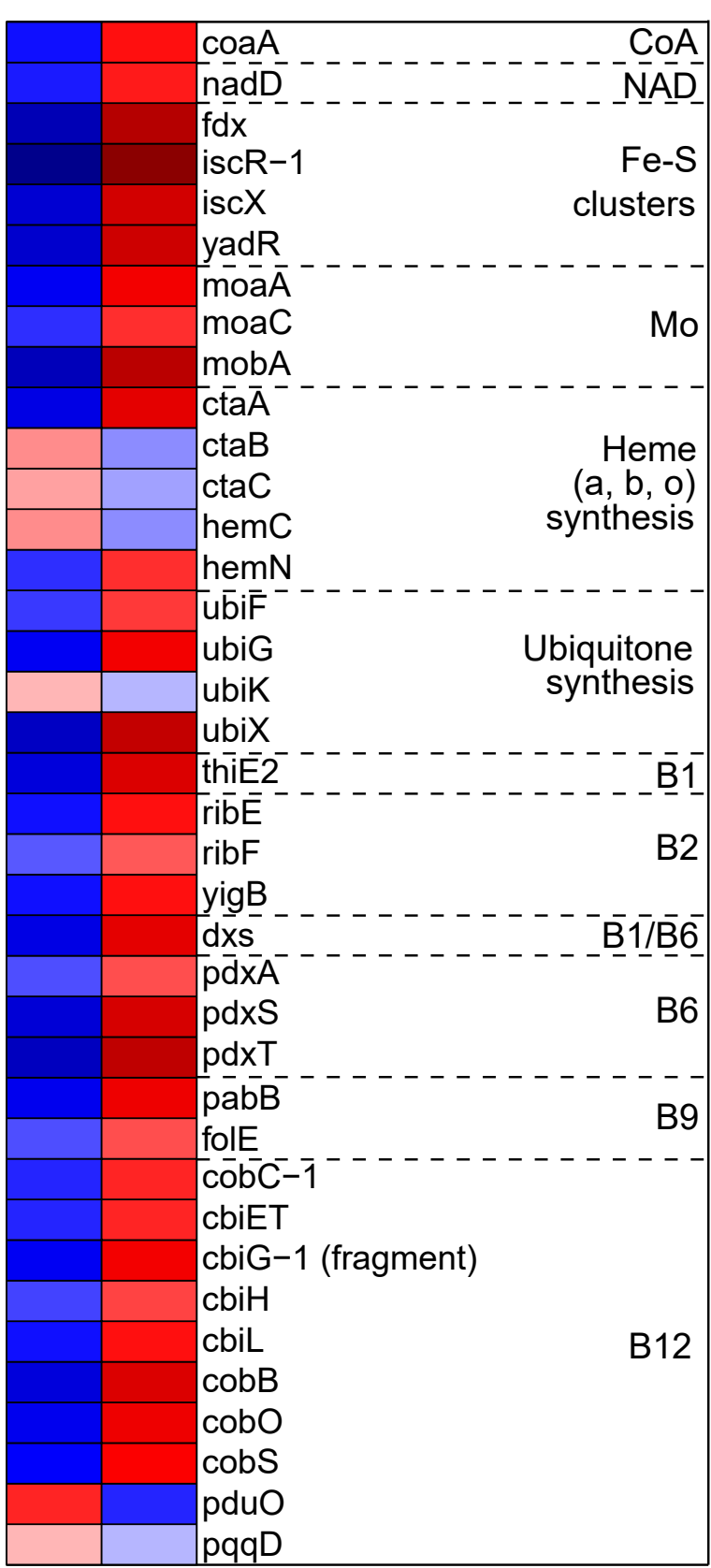

B

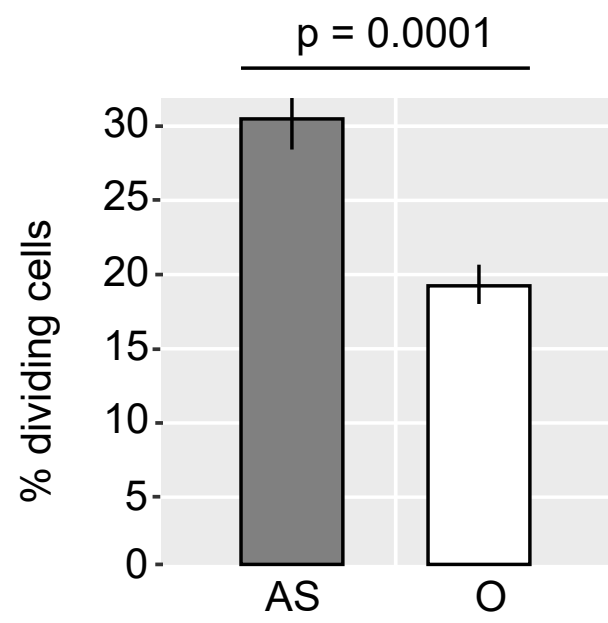

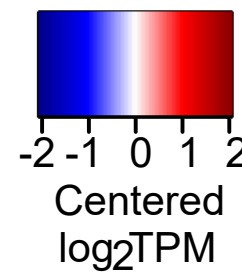

TIR-domain-containing-3 


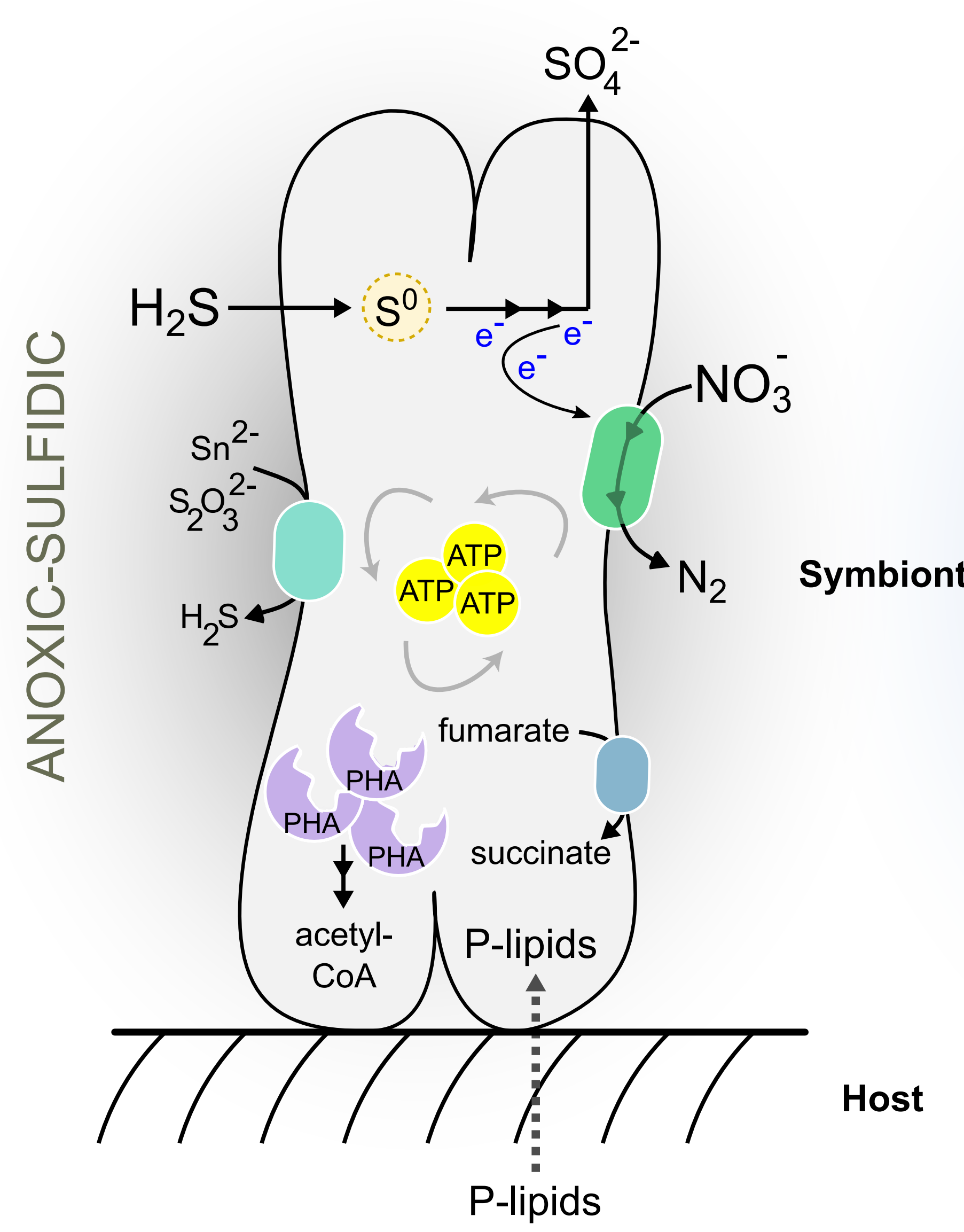

